\title{
Local Connections of Excitatory Neurons to Corticothalamic Neurons in the Rat Barrel Cortex
}

\author{
Yasuhiro R. Tanaka, ${ }^{1}$ Yasuyo H. Tanaka, ${ }^{1}$ Michiteru Konno, ${ }^{1}$ Fumino Fujiyama, ${ }^{1,2}$ Takahiro Sonomura, ${ }^{3}$ \\ Keiko Okamoto-Furuta, ${ }^{1}$ Hiroshi Kameda, ${ }^{1}$ Hiroyuki Hioki, ${ }^{1}$ Takahiro Furuta, ${ }^{1}$ Kouichi C. Nakamura, ${ }^{1}$ \\ and Takeshi Kaneko ${ }^{1}$ \\ ${ }^{1}$ Department of Morphological Brain Science, Graduate School of Medicine, Kyoto University, Kyoto 606-8501, Japan, ${ }^{2}$ Japan Science and Technology \\ Agency (JST), Core Research for Evolutional Science and Technology (CREST), Tokyo 102-0075, Japan, and ${ }^{3}$ Department of Anatomy for Oral Sciences, \\ Graduate School of Medical and Dental Sciences, Kagoshima University, Kagoshima 890-8544, Japan
}

Corticothalamic projection neurons in the cerebral cortex constitute an important component of the thalamocortical reciprocal circuit, an essential input/output organization for cortical information processing. However, the spatial organization of local excitatory connections to corticothalamic neurons is only partially understood. In the present study, we first developed an adenovirus vector expressing somatodendritic membrane-targeted green fluorescent protein. After injection of the adenovirus vector into the ventrobasal thalamic complex, a band of layer (L) 6 corticothalamic neurons in the rat barrel cortex were retrogradely labeled. In addition to their cell bodies, fine dendritic spines of corticothalamic neurons were well visualized without the labeling of their axon collaterals or thalamocortical axons. In cortical slices containing retrogradely labeled L6 corticothalamic neurons, we intracellularly stained single pyramidal/spiny neurons of L2-6. We examined the spatial distribution of contact sites between the local axon collaterals of each pyramidal neuron and the dendrites of corticothalamic neurons. We found that corticothalamic neurons received strong and focused connections from L4 neurons just above them, and that the most numerous nearby and distant sources of local excitatory connections to corticothalamic neurons were corticothalamic neurons themselves and L6 putative corticocortical neurons, respectively. These results suggest that L4 neurons may serve as an important source of local excitatory inputs in shaping the cortical modulation of thalamic activity.

\section{Introduction}

The primary sensory cortex, consisting of six layers, receives thalamocortical projections principally in layer (L) 4 and sends corticothalamic projections mainly from L6, constituting the thalamocortical reciprocal circuit with the corresponding thalamic nucleus (Jones, 1984; Deschênes et al., 1998; Douglas et al., 2004; Sherman and Guillery, 2006; Shipp, 2007; Fox, 2008; Thomson, 2010). In this reciprocal circuit, L6 corticothalamic projection neurons (CTNs) are considered to enhance and tune

Received June 20, 2011; revised Oct. 14, 2011; accepted Oct. 24, 2011.

Author contributions:Y.R.T. and T.K. designed research;Y.R.T., Y.H.T., M.K., and K.O.-F. performed research; T.S., H.K., H.H., T.F., and K.C.N. contributed unpublished reagents/analytic tools; Y.R.T. and F.F. analyzed data; Y.R.T. and T.K. wrote the paper.

This work was supported by The Ministry of Education, Culture, Sports, Science and Technology of Japan (T.K. Grants 22300113, 23650175, 23115101; H.H, 18700341; Y.R.T., 08J03974). We are grateful to Mr. H. Kohda for technical assistance in electron microscopy; to Drs. Ryohei Tomioka and Nobuaki Tamamaki for advice on the production of adenovirus; and to Drs. Shuzo Sakata and Roberto Gavinio for comments on the manuscript.

Correspondence should be addressed to Dr. Takeshi Kaneko, Department of Morphological Brain Science, Graduate School of Medicine, Kyoto University, Kyoto 606-8501, Japan. E-mail: kaneko@mbs.med.kyoto-u.ac.jp.

Y.R. Tanaka's and Y.H. Tanaka's present address: Division of Brain Circuits, National Institute for Basic Biology, Okazaki 444-8585, Japan

H. Kameda's present address: Department of Physiology, Teikyo University School of Medicine, Tokyo 173-8605, Japan.

K.C. Nakamura's present address: Medical Research Council Anatomical Neuropharmacology Unit, University of Oxford, Oxford OX1 3TH, UK.

DOI:10.1523/JNEUROSCI.3139-11.2011

Copyright $\odot 2011$ the authors $\quad 0270-6474 / 11 / 3118223-14 \$ 15.00 / 0$ thalamic responses to peripheral stimuli (Yuan et al., 1986; Yan and Suga, 1996; Przybyszewski et al., 2000; Alitto and Usrey, 2003; Temereanca and Simons, 2004; Thomson, 2010). Local connections between cortical layers are well developed (Briggs and Callaway, 2001; Mercer et al., 2005; Zarrinpar and Callaway, 2006; West et al., 2006; Lefort et al., 2009; Llano and Sherman, 2009; Lam and Sherman, 2010; Hooks et al., 2011), and in addition to external inputs, local translaminar inputs are involved in shaping CTN activity. Therefore, the laminar organization of local excitatory inputs to CTNs may be important for cortical modulation of thalamic activity.

It is widely accepted that columnar modules serve as elementary units of information processing in the cerebral cortex, especially in the primary sensory cortices (Mountcastle, 1997). The rodent primary somatosensory (S1) barrel cortex, where L4 neurons assemble barrel-like structures, processes sensory information from facial whiskers (Fox, 2008). Neurons in the L4 barrel (300-400 $\mu \mathrm{m}$ in diameter) and those in the other layers respond primarily to a single whisker, thus congregating in a vertical column extending across the cortical layers. Furthermore, recent studies have revealed that a single barrel includes several neuronal clusters $(\sim 100 \mu \mathrm{m}$ in diameter $)$ that contain neurons showing similar preferences for the direction of whisker deflection, suggesting that a barrel column is further divided into functional substructures (Bruno et al., 2003; Andermann and Moore, 2006). Because cortical local connections often spread tangentially or 
horizontally beyond these structures, it is important to examine the horizontal organization of local excitatory inputs to CTNs, in addition to laminar organization.

Here, we retrogradely labeled CTNs with a newly developed adenoviral vector expressing a somatodendritic membranetargeted green fluorescent protein (GFP), which was useful in visualizing CTNs from their cell bodies to fine dendritic spines. Combining the retrograde labeling method with an intracellular recording/staining technique in brain slices, we examined the distribution of contact sites between the axons of single pyramidal/spiny neurons and the dendrites of a multitude of CTNs in the rat barrel cortex. Finally, we made a morphological estimation of the interlaminar and horizontal organization of local excitatory connections to CTNs.

\section{Materials and Methods}

All procedures in the experiments were conducted in accordance with the Committee for Animal Care and Use and that for Recombinant DNA Study in Kyoto University. One hundred and two male Wister rats (weight, 250-350 g; age, 8-12 postnatal weeks; Japan SLC) were used in the present study. All efforts were made to minimize the number of animals used and their suffering.

\section{Adenoviral vector}

The adenoviral vector plasmid (Fig. $1 A$ ) was constructed and produced according to Virapower adenoviral promoterless gateway expression kit (Invitrogen). Enhanced human synapsin I promoter (E/SYN) (Hioki et al., 2007), GFP with an N-terminal myristoylation site of Fyn protein and with a C-terminal portion of low-density lipoprotein receptor (myrGFPLDLRct) (Kameda et al., 2008), woodchuck hepatitis virus posttranscriptional regulatory element (WPRE; nucleotides 1093-1684 of gb: U57609; a gift from Dr. Hope, Department of Cell and Molecular Biology, Northwestern University Medical School, Chicago, IL) (Zufferey et al., 1999), and polyadenylation signal from bovine growth hormone (BGHpA) were subcloned into pENTR1 vector (Invitrogen). The insert (E/SYNmyrGFP-LDLRct-WPRE-BGHpA) was transferred to the adenoviral backbone ( $\mathrm{pAd} / \mathrm{PL}-\mathrm{DEST}$ ) by homologous recombination by LR clonase (Invitrogen), resulting pAd-E/SYN-myrGFP-LDLRct-BGHpA. Adenoviral vector was produced according to the manufacture's protocol and purified as described previously (Tomioka and Rockland, 2006). Obtained viral stocks in $0.6 \mathrm{M} \mathrm{NaCl}$ were stored in $-80^{\circ} \mathrm{C}$ until use. The final viral stocks typically have the titer of $10^{10}-10^{11}$ gene transfer unit $(\mathrm{GTU}) / \mathrm{ml}$. For titration of the viral stocks, we disseminated serially diluted viral solutions to $90 \%$ confluent HEK cells in 6 well plates. Two days after dissemination, cells were fixed and immunostained with anti-GFP antibody. The titer was determined by counting GFP-immunopositive cells.

\section{Surgery}

Rats were anesthetized through an intraperitoneal injection of $7 \%$ $(\mathrm{w} / \mathrm{v})$ chloral hydrate. For the analysis of the connection of single pyramidal neurons to corticothalamic neurons, $2 \mu \mathrm{l}$ of $0.6 \mathrm{M} \mathrm{NaCl}$ containing adenoviral vector (Tomioka and Rockland, 2006) was injected very slowly for $30 \mathrm{~min}$ into the right ventrobasal thalamic complex by pressure through a glass micropipette equipped with a picospritzer III (Parker Hannifin Corporation, General Valve Division). Air pressure, duration, and frequency were set at $40 \mathrm{psi}, 5-10$ $\mathrm{ms}$, and $0.1-1.0 \mathrm{~Hz}$, respectively. For the assessment of the labeling efficiency by retrograde tracers, $1 \mu \mathrm{l}$ of $0.6 \mathrm{M} \mathrm{NaCl}$ containing adenoviral vector (Tomioka and Rockland, 2006), $0.2 \mu \mathrm{l}$ of $1 \%$ (w/v) Cholera toxin B subunit (List Biological Laboratories) in $10 \mathrm{~mm}$ PBS, $\mathrm{pH}$ 7.4 , or $0.2 \mu \mathrm{l}$ of $4 \%$ (w/v) Fluorogold (Fluochrome) in distilled water was injected.

\section{Assessment of the efficiency of retrograde labeling}

Methods for fixation and immunofluorescence were described previously (Kuramoto et al., 2007) and antibodies/reagents/filter sets used in the detection of retrograde tracers and $\mathrm{NeuN}$, a neuron-specific marker, are summarized in Table 1. Under a confocal laser-scanning microscope (LSM 5 Pascal; Carl Zeiss), images were serially taken through the thickness of sections $(30 \mu \mathrm{m})$ with the optical thickness of $1.8 \mu \mathrm{m}$ (corresponding to pinhole of 1 Airy unit), using an oil-immersion $\times 63$ objective lens (PlanNEOFLUAR, numerical aperture 1.40). We divided the number of NeuN/ GFP (or other tracers) double-positive cells by the number of NeuN-positive cells, to obtain the rate of the retrograde labeling. Cells were counted stereologically in all cases (Howard and Reed, 1998).

\section{In vitro intracellular recording}

Rats were allowed to survive for 6-14 d after operation, again anesthetized deeply by ether inhalation, and decapitated. Slices were prepared as described previously (Cho et al., 2004a) with slight modifications. To retain neuronal viability in slices, we used $N$-methyl-D-glucamine-based cutting solution (Tanaka et al., 2008), which contained (in mM) 147 $\mathrm{N}$-methyl-D-glucamine, $20 \mathrm{HEPES}, 1 \mathrm{KCl}, 1.3 \mathrm{KH}_{2} \mathrm{PO}_{4}, 2.5 \mathrm{MgSO}_{4}, 1$ $\mathrm{CaCl}_{2}, 10$ glucose ( $\mathrm{pH}$ was adjusted to 7.4 by $\mathrm{HCl}$ ). The brains were removed quickly and cut frontally into $500-\mu \mathrm{m}$-thick slices in the cutting solution saturated with $95 \% \mathrm{O}_{2}$ and $5 \% \mathrm{CO}_{2}$. The cutting direction was optimized in the preliminary experiments to be parallel to the apical dendrites of pyramidal neurons.

Cortical slices were placed at $34-35^{\circ} \mathrm{C}$ in an interface chamber and perfused with ACSF, which was composed of (in mM) $124 \mathrm{NaCl}, 3.3 \mathrm{KCl}$, $1.3 \mathrm{KH}_{2} \mathrm{PO}_{4}, 26 \mathrm{NaHCO}_{3}, 1 \mathrm{MgSO}_{4}, 2.5 \mathrm{CaCl}_{2}$, and 10 glucose ( $\mathrm{pH}$ was 7.4 when saturated with $95 \% \mathrm{O}_{2}$ and $5 \% \mathrm{CO}_{2}$ gas). Glass microelectrodes were made with a puller (P-97; Sutter) and filled with 3\% (w/v) biocytin (Sigma) dissolved in $2 \mathrm{M} \mathrm{KCH}_{3} \mathrm{SO}_{4}$ and $50 \mathrm{~mm}$ Tris- $\mathrm{HCl}$, $\mathrm{pH}$ 7.4. The resistance of the electrodes was typically $80-100 \mathrm{M} \Omega$. To maximize the morphological recovery of neuronal processes, we recorded neurons in the middle two fifth of the slice thickness (150-350 $\mu \mathrm{m}$ from the slice cut surface) in the cortical slices where successful retrograde labeling of L6 was checked by an epifluorescence microscopy.

With the help of the fluorescence microscope and stereomicroscope, we moved the recording electrode into the region containing many retrogradely labeled neurons. After impalement, the response of the pyramidal neuron to current injection was recorded with a current-clamp amplifier (IR-183; Cygnus Technology) and stored in a computer through an analog-digital converter (PowerLab; ADInstruments). Before releasing the impaled neuron, biocytin was injected by passing 200-ms-long, $0.1-0.5 \mathrm{nA}$ positive pulses at $2.0 \mathrm{~Hz}$. In most cases, only one neuron was impaled in a slice to avoid an overlap of dendritic or axonal arbors of two or more neurons. After recording, the slices were further incubated for $1-4 \mathrm{~h}$ and fixed for $20 \mathrm{~h}$ at $24-25^{\circ} \mathrm{C}$ in $0.1 \mathrm{M}$ sodium phosphate, $\mathrm{pH} 7.4$, containing $3 \%(\mathrm{w} / \mathrm{v})$ formaldehyde, $0.01 \%(\mathrm{w} / \mathrm{v})$ glutaraldehyde, and 75\%-saturated picric acid.

\section{Double peroxidase staining}

After cryoprotection with $30 \%(\mathrm{w} / \mathrm{v})$ sucrose in PBS, the slices were further cut into $25-\mu \mathrm{m}$-thick sections on a freezing microtome. In the following procedures, each section was separately incubated in a well at room temperature. All the reagents of the following incubations were resolved in PBS containing 0.3\% (v/v) Triton X-100 and $0.02 \%(\mathrm{w} / \mathrm{v})$ sodium merthiolate unless otherwise stated, and an incubation was followed by several rinses with PBS containing $0.3 \%(\mathrm{v} / \mathrm{v})$ Triton X-100. The sections were: (1) soaked for $30 \mathrm{~min}$ in $1 \%(\mathrm{v} / \mathrm{v}) \mathrm{H}_{2} \mathrm{O}_{2}$ in PBS to suppress endogenous peroxidase activity in the tissue, (2) incubated for 30 min with $10 \%$ (v/v) normal donkey serum (Millipore), (3) incubated for at least $12 \mathrm{~h}$ with a mixture of avidin-biotinylated peroxidase complex (ABC; 1:50; PK-6100, Vector Laboratories), $0.5 \mu \mathrm{g} / \mathrm{ml}$ Alexa Fluor 594conjugated StreptAvidin (Invitrogen) and $0.5 \mu \mathrm{g} / \mathrm{ml}$ affinity-purified anti-GFP rabbit antibody (Tamamaki et al., 2000; Nakamura et al., 2008), (4) observed under an epifluorescence microscope (Axiophot; Carl Zeiss) to determine which section contained the cell body of the biocytin-injected neuron, (5) incubated for 30-60 min with $0.02 \%(\mathrm{w} / \mathrm{v})$ diaminobenzidine-4HCl (DAB; Dojindo Laboratories), $10 \mathrm{~mm}$ nickel ammonium sulfate, and $0.0001 \%$ (v/v) $\mathrm{H}_{2} \mathrm{O}_{2}$ in $50 \mathrm{~mm}$ Tris- $\mathrm{HCl}$, $\mathrm{pH}$ 7.6, for visualization of the intracellularly labeled neuron followed by rinses with $50 \mathrm{~mm}$ Tris- $\mathrm{HCl},(6)$ incubated for $30 \mathrm{~min}$ with $2 \%(\mathrm{w} / \mathrm{v}) \mathrm{NaN}_{3}$ in 50 $\mathrm{mm}$ Tris- $\mathrm{HCl}$ to inactivate peroxidase attached to biocytin, (7) incubated 


\section{A}
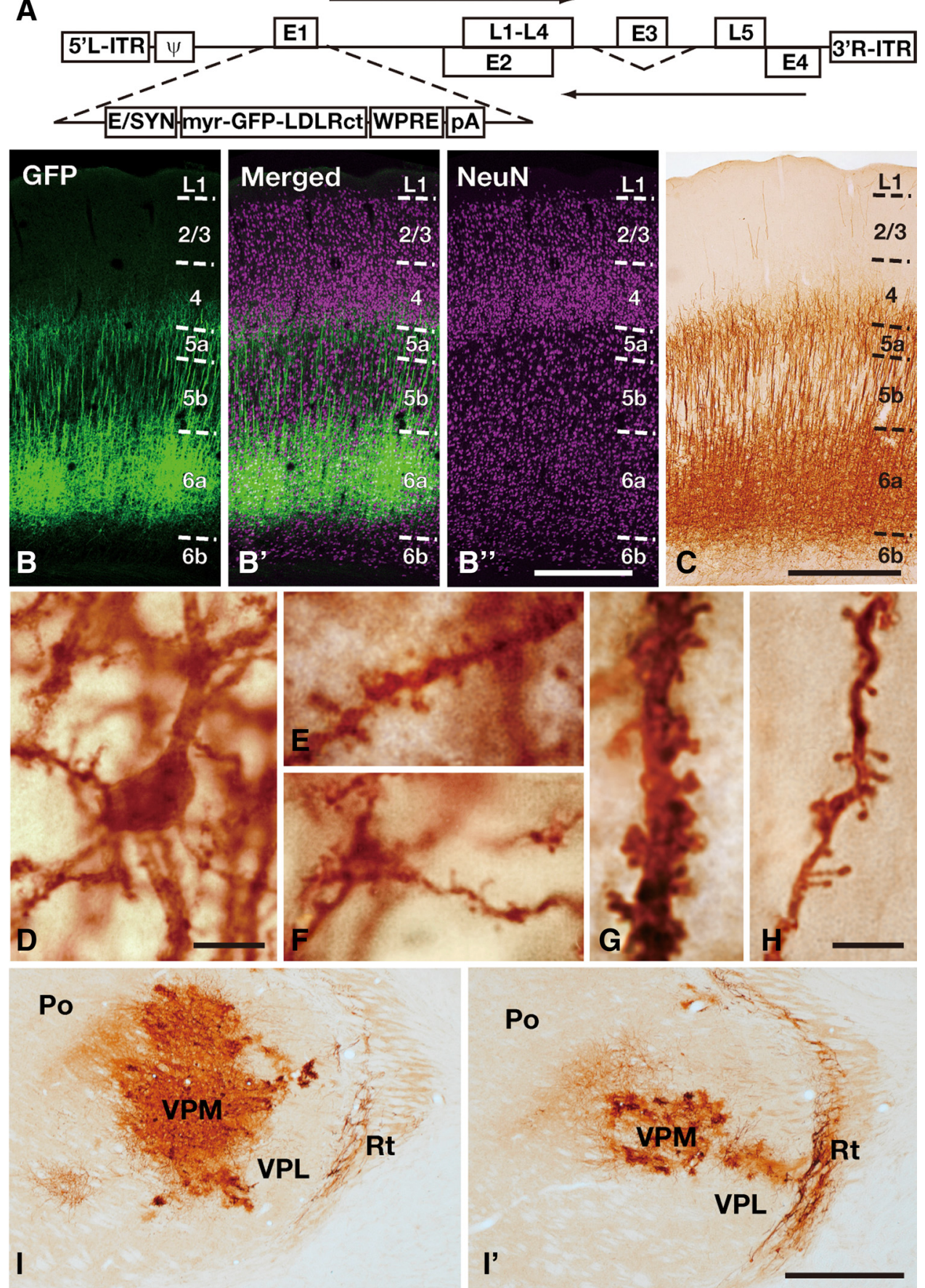

Figure 1. Retrograde labeling of corticothalamic neurons with adenoviral vector. $A$, Construction of the adenoviral vector expressing somatodendritic membrane-targeted GFP. ITR, Inverted terminal repeat; $\psi$, packaging signal; E1-5, early regions $1-5 ; \mathrm{L} 1-5$, late regions 1-5; pA, poly-adenylation signal. $B, C$, L6a neurons of the barrel cortex were retrogradely immunolabeled 1 week after injection of adenoviral vector expressing somatodendritic membrane-targeted GFP into the ventrobasal thalamic nucleus. GFP immunoreactivity was visualized either with Alexa Fluor 488 ( $\boldsymbol{B}$ ) or with $\mathrm{DAB}\left(\boldsymbol{C}\right.$. NeuN immunoreactivity was also visualized with Alexa Fluor $647\left(\boldsymbol{B}^{\prime}, \boldsymbol{B}^{\prime \prime}\right)$ to clarify the cortical cytoarchitecture. $\boldsymbol{D}-\boldsymbol{H}$, At higher magnification, immunolabeling of GFP successfully visualized cell bodies $(\boldsymbol{D})$, basal dendritic branches $(\boldsymbol{E}, \boldsymbol{F})$, apical dendritic shafts $(\boldsymbol{G})$, and apical dendritic tufts $(\boldsymbol{H})$ of (TNs. Note that no obvious axonal fibers were found. $\left(\boldsymbol{I}, \boldsymbol{I}^{\prime}\right)$ Dense neuronal and glial processes were found in and around the injection site $(\boldsymbol{I})$ and cells in reticular thalamic nucleus (Rt) were also labeled $\left(\boldsymbol{I}, \boldsymbol{I}^{\prime}\right)$. The photograph in $\boldsymbol{I}^{\prime}$ was taken $300 \mu \mathrm{m}$ anterior to that in $I$. Po, Posterior thalamic nuclei; VPM, ventral posteromedial thalamic nucleus; VPL, ventral posterolateral thalamic nucleus; Rt, thalamic reticular nucleus. Scale bars: (in $\left.\boldsymbol{B}^{\prime \prime}\right) \boldsymbol{B}-\boldsymbol{B}^{\prime \prime}, 500 \mu \mathrm{m} ; \boldsymbol{C}, 500 \mu \mathrm{m}$; $D, 10 \mu \mathrm{m} ;$ (in $\boldsymbol{H}), \boldsymbol{E}-\boldsymbol{H}, 5 \mu \mathrm{m} ;$ (in $\left.\boldsymbol{I}^{\prime}\right) \boldsymbol{I}, \boldsymbol{I}^{\prime}, 500 \mu \mathrm{m}$.

for $1 \mathrm{~h}$ with $10 \mu \mathrm{g} / \mathrm{ml}$ biotinylated anti-rabbit IgG goat antibody (Vector Laboratories), (8) incubated for $1 \mathrm{~h}$ with $\mathrm{ABC}$ (1:150), (9) incubated for 30 min with $0.6 \mu \mathrm{M}$ biotinylated tyramine in $50 \mathrm{~mm}$ sodium phosphate buffer, pH 7.4, containing $3 \mu \mathrm{g} / \mathrm{ml}$ glucose oxidase (259 U/mg; Nacalai Tesque) and $2 \mathrm{mg} / \mathrm{ml} \beta$-D-glucose (Nacalai Tesque) for further signal enhancement of GFP immunoreactivity (Furuta et al., 2009; Kuramoto et al., 2009), (10) incubated for $1 \mathrm{~h}$ with $\mathrm{ABC}(1: 10,000)$ again, (11) incubated for 30-60 min with $0.02 \%$ DAB and $0.001 \%(\mathrm{v} / \mathrm{v}) \mathrm{H}_{2} \mathrm{O}_{2}$ in 50 mм Tris- $\mathrm{HCl}, \mathrm{pH} 7.6$ for visualization of retrogradely labeled neurons, and (12) mounted on gelatin-coated glass slides, dehydrated with an ethanol series, cleared in xylene, and coverslipped with organic mounting medium MX (Matsunami).

After the step (4), the section containing the cell body of the impaled neuron was incubated with $5 \mu \mathrm{g} / \mathrm{ml}$ Alexa Fluor 488-conjugated anti- 
Table 1. Summary of antibodies/reagents/filters used for the detection of retrograde tracers

\begin{tabular}{|c|c|c|c|c|c|}
\hline & GFP & Cholera toxin B subunit & Fluorogold & NeuN & \\
\hline \multicolumn{6}{|l|}{ Primary antibody } \\
\hline Host & Rabbit & Goat & Rabbit & Mouse & \\
\hline Concentration & $1 \mu \mathrm{g} / \mathrm{ml}$ & $1: 500$ & $1: 500$ & $2 \mu \mathrm{g} / \mathrm{ml}$ & \\
\hline \multicolumn{6}{|l|}{ Secondary antibody } \\
\hline Target & Rabbit lgG & Goat $\lg G$ & Rabbit lgG & Mouse lgG & Mouse $\lg G$ \\
\hline Host & Goat & Donkey & Goat & Goat & Donkey \\
\hline Source & Vector & Jackson ImmunoResearch Laboratories & Invitrogen & Invitrogen & Jackson ImmunoResearch Laboratories \\
\hline Other reagents & Streptavidin & & & & \\
\hline Label & Alexa Fluor 488 & & & & \\
\hline Concentration & $5 \mu \mathrm{g} / \mathrm{ml}$ & & & & \\
\hline Source & Invitrogen & & & & \\
\hline Excitation beam & $488 \mathrm{~nm}$ & 543 & 543 & 633 & \\
\hline
\end{tabular}

rabbit IgG goat antibody (Invitrogen) and $1 \mu \mathrm{g} / \mathrm{ml} \mathrm{4}$, 6-diamidino-2phenylindole (DAPI; Invitrogen) for $1 \mathrm{~h}$. This section was observed again under the epifluorescence microscope with filter sets for DAPI (359-371 $\mathrm{nm}$ excitation and 397-490 nm emission), Alexa Fluor $488(450-490 \mathrm{~nm}$ excitation and 515-565 nm emission), and Alexa Fluor 594 (530-585 nm excitation and $\geq 615 \mathrm{~nm}$ emission) to determine which layer the impaled neuron was located at, whether it expressed GFP or not, and how dense the retrograde labeling was in this slice. The section was then incubated for $1 \mathrm{~h}$ with $0.5 \mu \mathrm{g} / \mathrm{ml}$ anti-GFP rabbit antibody again, to recover GFP immunoreactivity that had been reduced by the incubation with the fluorescent-conjugated secondary antibody. After these additional steps, the section returned to the step (5).

\section{Data analysis}

Analyses of neuronal processes and bouton distribution. Slices collected for analyses met all the following criteria: (1) CTNs in the posteromedial barrel subfield were sufficiently labeled ( $>50 \%$ of L6a neurons), (2) stained axons of the intracellularly labeled cell did not fade, and (3) slices did not show clear damage, except at the slice cut surface. Because $\sim 60 \%$ of L6a neurons were labeled after massive injections of retrograde tracers into the thalamus (see Results), the condition (1) ensures that $>80 \%$ of L6 CTNs were labeled in the analyzed region $(50 / 60=0.83)$. Five neurons from each of L2/3, L4, L5b, L6 GFP-positive (L6+), and L6 GFPnegative (L6-) groups and three neurons from L5a group were analyzed (see also Results). First, neuronal processes of an intracellularly stained neuron projected onto the frontal plane were reconstructed using the camera lucida method with a light microscope and an attached drawing tube. After 2D-reconstruction of neuronal processes, we plotted the cell body and boutons of intracellularly labeled neurons by using Neurolucida (MBF Bioscience) installed on a microscope (VANOX; Olympus) with an oil-immersion $\times 100$ objective lens (PLAN Apo, numerical aperture 1.35) and 30 inch monitor (resultant magnification was $\times 5000$ ). When axon varicosities were $\geq 1.5$-fold thicker than intervaricose fibers, they were presumed to be presynaptic axon boutons in the present study. During plotting, we carefully examined whether or not each bouton was apposed to a CTN dendrite, while moving the plane of focus up and down.

The data of three-dimensional distribution of axon boutons were analyzed using IgorPro 5.05 (WaveMetrics). Because $z$-axis, which is perpendicular to the section surface, was shrunken through the poststaining procedure (i.e. mounting, dehydration, and clearing), we corrected the $z$-axis depths by dividing them with the shrinkage factors ( $=$ [the actual thickness of mounted sections in $\mu \mathrm{m}] /[25 \mu \mathrm{m}]$ ). We measured horizontal distance $(x)$ between each axon bouton and the cell body of its origin. Horizontal distance was measured after projection onto the L4/5 boundary plane, compensating for the curvature of the rat cerebral cortex. Relative frequency histograms for $x$ of apposed boutons were fitted with a mixture of gamma distributions, $x \cdot \exp (-x / \beta)$. Fitting was performed by maximum likelihood estimation and the model (i.e., how many gamma distributions were mixed) was selected by the Bayesian information criterion (Schwarz, 1978). All histograms were best fitted with a single gamma distribution, except in the case of three L4 neurons and three L $5 \mathrm{~b}$ neurons. The vertical location of boutons was transformed in a linear normalized scale in which the pia mater was set to 0.0 and the white matter border was to 1.0 .

For analysis of the distance between descending axons and dendritic bundles, we plotted descending axons of L2/3 and L4 neurons as well as dendritic bundles around those descending axons with Neurolucida. The three-dimensional Euclidian distance between the center of the nearest dendritic bundle and the axon was measured and the minimal value was used as the distance to the nearest dendritic bundle center.

Morphological estimation of local excitatory inputs to L6 CTNs. We counted apposed boutons located in the hollow cylindrical interval between horizontal distances $x$ and $x+1(\mu \mathrm{m})$ from the cell body of a single pyramidal/spiny neuron and divided this number by the area of this cylindrical interval, $\pi\left\{(x+1)^{2}-x^{2}\right\}$. The obtained density was defined as $a(x, y)$, where $y$ is the normalized vertical location at which the pyramidal/spiny neuron's cell body was located. The density $a(x, y)$ can also be seen as a density of apposed boutons originating from a pyramidal/ spiny neuron at $(x, y)$, where horizontal distance $x$ is measured from CTN dendrites receiving these apposed boutons (see also Results for underlying suppositions). Multiplying $a(x, y)$ by $n(y)$, the density of pyramidal/ spiny neurons at $y$, we obtained $i(x, y)$, which indicates how many numbers of apposed boutons on CTN dendrites in a slender square prism $\left(1 \times 1 \mu \mathrm{m}^{2}\right.$ base; located at $\left.x=0\right)$ are originating from neurons within a small cube at $(x, y)$ as shown in Figure $8 B$. To compensate the effect of slice cutting, when $x$ is $>250(\mu \mathrm{m})$, we corrected $a(x, y)$ by dividing it with the correction factor, $2 \frac{\sin ^{-1}\left(\frac{250}{x}\right)}{x} \cdot n(y)$ was determined by stereological counting (Howard and Reed, 1998) of vesicular glutamate transporter 1-positive cells in each layer that were labeled by in situ hybridization (Nakamura et al., 2007) with the counterstain of neuronal cell bodies. $n(y)$ was $52,340 \pm 4831 / \mathrm{mm}^{3}$ for $0.06<y<0.23$ (L2/3), $78,364 \pm 2680$ for $0.23<y<0.38$ (L4), $26,706 \pm 6198$ for $0.38<y<$ 0.45 (L5a), 37,350 \pm 2145 for $0.45<y<0.62$ (L5b), and 51,755 \pm 5840 for $0.62<y<0.91$ (L6a) (mean $\pm \mathrm{SD}, N=3$ ). We discretized $y$ into 15 segments and allocated $a(x, y)$ obtained from 25 neurons. For segments with two or more neurons, $a(x, y)$ was obtained by averaging the sets of $a(x, y)$ of contained neurons.

$I_{\mathrm{L}}\left[x_{1}, x_{2}\right]$ represents how many apposed boutons on CTN dendrites in a slender prism $\left(1 \times 1 \mu \mathrm{m}^{2}\right.$ base $)$ are originating from a group of pyramidal/spiny neurons ( $\mathrm{L}=\mathrm{L} 2 / 3, \mathrm{~L} 4, \mathrm{~L} 5 \mathrm{a}, \mathrm{L} 5 \mathrm{~b}, \mathrm{~L} 6+$, or L6-) located in the hollow cylinder whose internal and external radii are $x_{1}$ and $x_{2}$, respectively (see Fig. 9A). $I_{\mathrm{L}}\left[x_{1}, x_{2}\right]$ could be obtained as $I_{\mathrm{L}}\left[x_{1}\right.$, $\left.x_{2}\right]=\int_{V} i(x, y) d v$, where $V$ was the volume of the hollow cylinder 
Table 2. Morphological properties of sampled cortical pyramidal neurons

\begin{tabular}{|c|c|c|c|c|c|c|}
\hline & \multicolumn{6}{|c|}{ Pyramidal neuron group } \\
\hline & $\mathrm{L} 2 / 3(n=5)$ & $L 4(n=5)$ & $\mathrm{L} 5 \mathrm{a}(n=3)$ & $\mathrm{L} 5 \mathrm{~b}(n=5)$ & $\mathrm{L} 6+(n=5)$ & $\mathrm{L} 6-(n=5)$ \\
\hline Soma area $\left(\mu \mathrm{m}^{2}\right)$ & $98.7 \pm 8.0$ & $84.0 \pm 9.6$ & $190.0 \pm 84.1^{*,+\dagger}$ & $243.8 \pm 70.8^{* *, \mathrm{t \dagger \dagger}}$ & $95.5 \pm 23.4^{\neq \neq, \S \S \S}$ & $100.5 \pm 7.7^{\ddagger \S \S \S}$ \\
\hline Horizontal span of apical dendrite $(\mu \mathrm{m})^{a}$ & $416.6 \pm 64.2$ & $138.5 \pm 49.1^{* * *}$ & $111.4 \pm 30.0^{* * *}$ & $432.4 \pm 98.5^{t+t, \neq \neq \neq}$ & $172.8 \pm 37.2^{* * *, \S \S \S}$ & $206.2 \pm 83.7^{* * *, \S \S \S}$ \\
\hline Horizontal span of basal dendrite $(\mu \mathrm{m})^{\mathrm{a}}$ & $274.8 \pm 42.6$ & $227.7 \pm 19.7$ & $361.2 \pm 27.7^{t \dagger}$ & $420.6 \pm 85.0^{* * *, t+t}$ & $214.0 \pm 34.5^{\ddagger \neq \neq, \S \S \S}$ & $314.7 \pm 44.8^{t, \S \S, 919}$ \\
\hline Total length of axon collaterals $(\mathrm{mm})^{b}$ & $26.92 \pm 7.39$ & $25.07 \pm 11.45$ & $29.5 \pm 6.3$ & $12.5 \pm 2.92^{*, 7}$ & $9.19 \pm 3.38^{* *, t, t \neq \neq}$ & $26.11 \pm 11.24^{\S, 991}$ \\
\hline Total number of boutons $(A)^{c}$ & $5918 \pm 2282$ & $5993 \pm 3243$ & $5408 \pm 1636$ & $1695 \pm 503^{* *, t t, \neq}$ & $1872 \pm 1012^{* *, t t, \neq}$ & $4675 \pm 2704^{\S}$ \\
\hline $\mathrm{B} / \mathrm{A}(\%)$ & $2.97 \pm 1.88$ & $5.89 \pm 2.50$ & $10.17 \pm 2.74$ & $21.54 \pm 2.59^{* * *,+\dagger}$ & $35.41 \pm 11.76^{* * *, t+t,+\neq \neq, \S}$ & $24.75 \pm 11.22^{* * *, t+t, \neq, q}$ \\
\hline
\end{tabular}

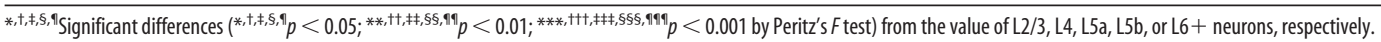

${ }^{a}$ The horizontal span and height of dendrites were measured in the frontal plane to which all the dendrites were projected.

${ }^{b}$ Total length of axon collaterals was estimated by multiplying the total length of axon collaterals projected onto the frontal plane by $\pi / 2$.

'Total number of boutons in L4 - 6 were counted and those in L1 -3 were estimated from length of axon collaterals and bouton density in L1 -3 (L2/3 neurons, $224.2 \pm 39.0 / \mathrm{mm} ; \mathrm{L} 4$ neurons, $269.6 \pm 38.3 / \mathrm{mm} ; \mathrm{L} 5 \mathrm{a}$ neurons, $229.8 \pm 52.7$ /mm; L5b neurons, $200.5 \pm 37.6 / \mathrm{mm})$.

Table 3. Electrophysiological properties of sampled cortical pyramidal neurons

\begin{tabular}{|c|c|c|c|c|c|c|}
\hline & \multicolumn{6}{|c|}{ Pyramidal neuron group } \\
\hline & $\mathrm{L} 2 / 3(n=5)$ & $\mathrm{L} 4(n=5)$ & L5a $(n=3)$ & $\mathrm{L} 5 \mathrm{~b}(n=5)$ & $\mathrm{L} 6+(n=5)$ & $\mathrm{L} 6-(n=5)$ \\
\hline Resting membrane potential (mV) & $-73.0 \pm 2.6$ & $-68.0 \pm 7.4$ & $-61.5 \pm 7.6$ & $-64.8 \pm 8.7$ & $-68.4 \pm 3.7$ & $-66.2 \pm 7.0$ \\
\hline Membrane time constant (ms) & $11.5 \pm 2.6$ & $7.5 \pm 4.5$ & $11.5 \pm 4.6$ & $11.7 \pm 5.1$ & $9.8 \pm 3.0$ & $7.9 \pm 2.6$ \\
\hline Input resistance $(M \Omega)$ & $51.1 \pm 27.5$ & $68.3 \pm 28.8$ & $65.3 \pm 34.4$ & $48.7 \pm 29.5$ & $62.2 \pm 18.1$ & $48.1 \pm 11.8$ \\
\hline Action potential (AP) threshold (mV) & $-47.6 \pm 7.9$ & $-41.3 \pm 15.6$ & $-40.2 \pm 7.2$ & $-50.6 \pm 10.5$ & $-41.4 \pm 5.1$ & $-43.1 \pm 7.1$ \\
\hline AP height $(\mathrm{mV})^{a}$ & $96.2 \pm 8.0$ & $103.8 \pm 10.2$ & $85.9 \pm 10.0$ & $97.9 \pm 5.7$ & $89.4 \pm 6.4$ & $94.0 \pm 16.8$ \\
\hline AP half width (ms) & $0.85 \pm 0.24$ & $0.86 \pm 0.39$ & $0.88 \pm 0.18$ & $0.72 \pm 0.29$ & $0.77 \pm 0.16$ & $0.71 \pm 0.13$ \\
\hline Fast afterpotential $(\mathrm{mV})^{b}$ & $2.7 \pm 2.8^{*, \neq \neq \neq}$ & $-1.5 \pm 2.0^{\dagger t, \neq}$ & $-3.9 \pm 3.0^{\mathrm{tt}}$ & 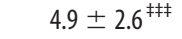 & $-6.1 \pm 3.3^{t+t}$ & $-1.1 \pm 3.0^{\mathrm{t}, \mathrm{t}}$ \\
\hline Slow afterpotential $(\mathrm{mV})^{b}$ & $-1.2 \pm 1.3$ & $-1.6 \pm 1.0$ & $-4.9 \pm 0.7$ & $-2.5 \pm 4.4$ & $-2.4 \pm 3.3$ & $-3.3 \pm 1.9$ \\
\hline
\end{tabular}

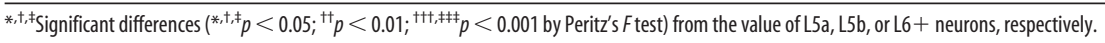

${ }^{a}$ AP height was measured from resting membrane potential.

${ }^{b}$ Fast and slow afterpotential was measured from baseline prior to action potential evoked by a short ( $<5 \mathrm{~ms}$ ) depolarizing pulse, at $3.3 \mathrm{~ms}$ or $29 \mathrm{~ms}$ from action potential onset, respectively. Pulse response without action potential to the same depolarizing pulse was recorded in another trace and subtracted. Our previous study showed that one type of $\mathrm{L} 6$ pyramidal neurons has a peak of fast afterhyperpolarization (AHP) at $3.3 \mathrm{~ms}$ on average, and that another type of $\mathrm{L} 6$ pyramidal neurons lacks fast AHP and has a peak of medium-range AHP at $29 \mathrm{~ms}$ on average (Kaneko et al., 1995).
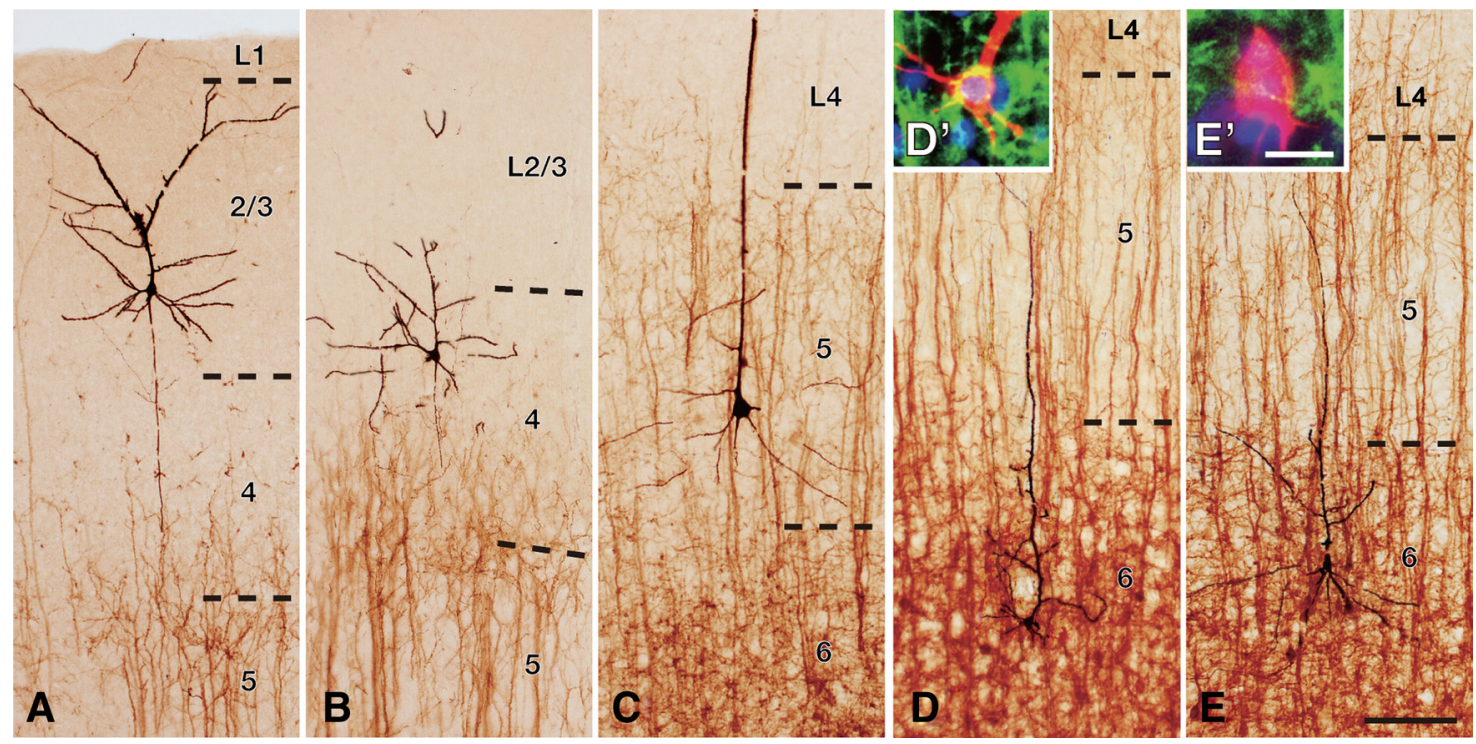

Figure 2. Combining intracellular staining with retrograde labeling of (TNs. $A-E$, Double immunoperoxidase staining of an intracellularly labeled neuron in $L 2 / 3(\boldsymbol{A}), \mathrm{L} 4(\boldsymbol{B}), \mathrm{L} 5(\boldsymbol{C})$, or $\mathrm{L} 6(\boldsymbol{D}, \boldsymbol{E})$ (black, nickel-enhanced DAB) and retrogradely labeled CTNs (brown, DAB). Intracellularly labeled L6 neurons were also visualized with fluorescence (red, biocytin; green, GFP; blue, DAPI) and classified as GFP-positive CTNs (L6+; $\left.\boldsymbol{D}, \boldsymbol{D}^{\prime}\right)$, or GFP-negative neurons ( $\left(\mathbf{6} 6-; \boldsymbol{E}, \boldsymbol{E}^{\prime}\right)$. Scale bars: (in $\left.\boldsymbol{E}\right) \boldsymbol{A}-\boldsymbol{E}, 100 \mu \mathrm{m}$; (in $\left.\boldsymbol{E}^{\prime}\right) \boldsymbol{E}^{\prime}, \boldsymbol{D}^{\prime}, 10 \mu \mathrm{m}$.

between distances $x_{1}$ and $x_{2}$ in each layer or sublayer. However, to assess the variability of the data, we first integrated $a(x, y) \cdot n(y)$ obtained from single pyramidal/spiny neurons and then averaged within each group. To obtain $n(y)$ for L6+ and L6- neurons, we estimated that $69 \%$ of excitatory neurons in L6a were corticothalamic neurons because $59 \%$ of L6a neurons were retrogradely labeled following a massive injection of retrograde tracer, and because $85 \%$ of neurons were positive for vesicular glutamate transporter 1 in L6a. On the other hand, $31 \%$ of L6a excitatory neurons were considered as corticocortical neurons (see also Results). 
Statistics. When we compared all pairs between the six pyramidal/spiny neuron groups (15 comparisons) we used Peritz's F test (Harper, 1984), a multiple-comparison test (Tables 2, 3; see Figs. 6, 9). For pairwise comparison in each neuron group, we used two-sided $t$ test with Bonferroni correction (see Fig. 7). Differences were accepted as significant if the family-wise type I error probability was $<0.05$. Each statistic and $p$ value was calculated with Prism 5.0 or programs written in Igor 5.05.

\section{Results}

\section{Retrograde labeling of CTNs with adenoviral vector}

To visualize CTN dendrites, we developed an adenoviral vector expressing myrGFPLDLRct (Kameda et al., 2008), a somatodendritic membrane-targeted GFP, under the control of an enhanced human synapsin I promoter (Hioki et al., 2007) (Fig. $1 A)$. After the adenoviral vector was injected with the vehicle containing $0.6 \mathrm{M}$ $\mathrm{NaCl}$ (Tomioka and Rockland, 2006) into the ventrobasal thalamic complex of rats, a band of L6 neurons in the S1 cortex was retrogradely labeled (Fig. $1 B, C$ ). As reported previously (Killackey and Sherman, 2003), labeled cells were mostly found in L6a, the upper part of L6 separated from L6b by cell-sparse fibrous zone (Fig. 1B) (Valverde et al., 1989). L5 corticothalamic neurons mainly projecting to posterior thalamic nuclei (Bourassa et al., 1995; Killackey and Sherman, 2003) were rarely labeled $(<1 \%$ in all GFP-positive neurons) and were negligible in subsequent analyses when the injection was confined to the ventrobasal complex. With this retrograde labeling method, not only the cell bodies and dendritic shafts of CTNs but the fine dendritic structures such as spines were visualized (Fig. $1 D_{-}$ $H)$. In contrast, almost no axon collaterals of retrogradely labeled neurons or anterogradely labeled thalamocortical axons were observed in the S1 cortex. Moreover, $\sim 60 \%$ of L6a neurons (i.e., $70 \%$ of L6a excitatory neurons) were labeled following vector injection $>3 \times 10^{6}$ GTU. Since this saturation level $(59.0 \pm 3.9 \%$; mean $\pm \mathrm{SD}, N=8$ ) was similar to the labeling efficiency of other potent retrograde tracers such as cholera toxin $\mathrm{B}$ subunit and Fluorogold $(58.6 \pm 11.0 \%, N=4$ and $57.6 \pm 8.9 \%, N=3 ; p=0.96$ by one-way ANOVA), almost all CTNs were considered to be visualized at least in the center of labeling. The labeling efficiency of adenovirus vector $\left(1 \times 10^{7} \mathrm{GTU}\right)$ did not significantly differ between postinjection survival times of 4,8 , and $16 \mathrm{~d}(56.1 \pm$ $2.6 \%, 58.1 \pm 5.6 \%$, and $59.8 \pm 1.1 \%, N=3$ each; $p=0.50$ by one-way ANOVA). Furthermore, thalamic neurons in and around the injection site in the ventrobasal thalamic complex were labeled, and some neurons in the thalamic reticular nucleus was labeled retrogradely (Fig. 1I).
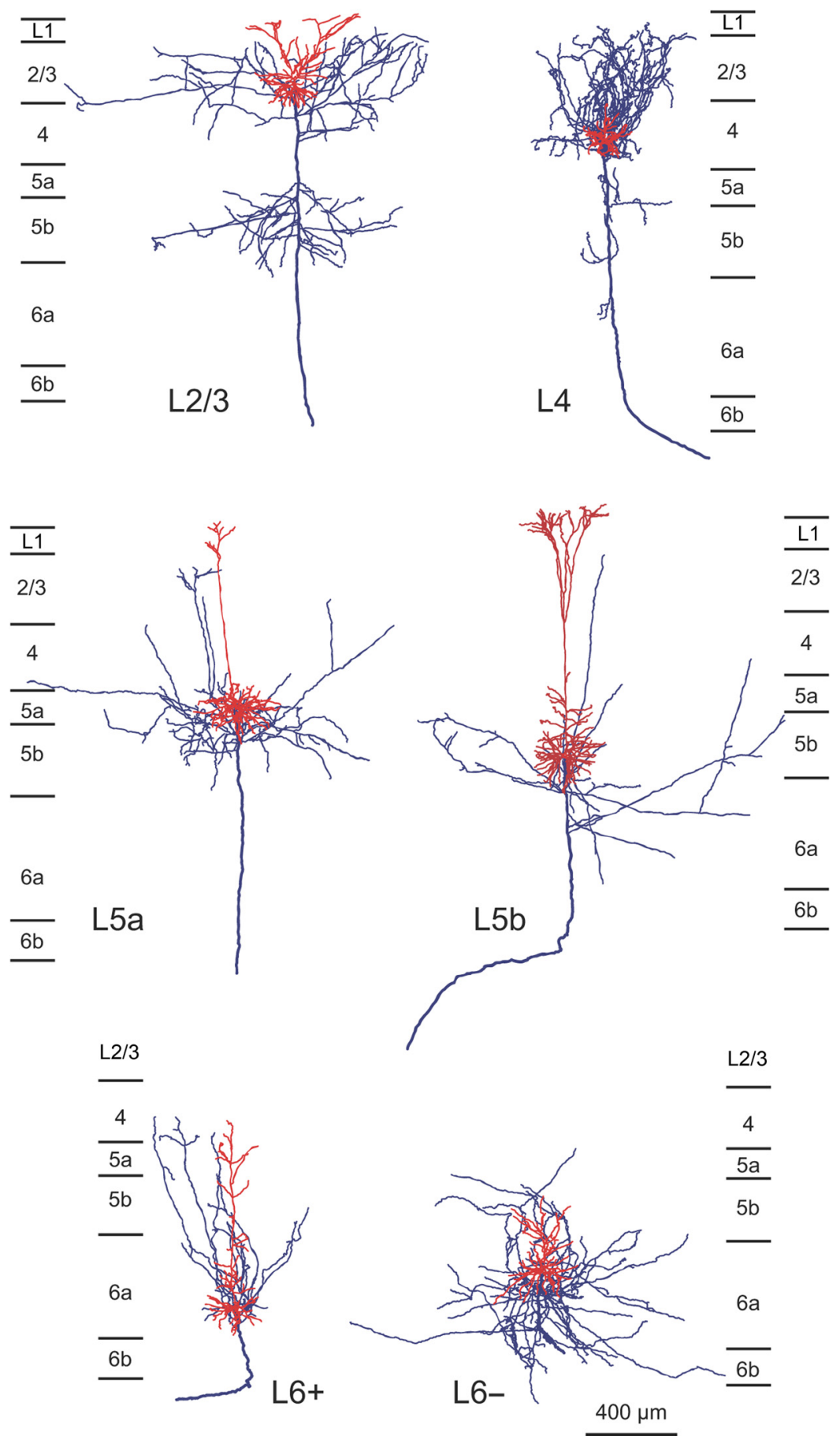

Figure 3. Two-dimensional reconstruction of intracellularly labeled neurons. Dendrites and axons originating from an $L 2 / 3, L 4$, $\mathrm{L} 5 \mathrm{a}, \mathrm{L} 5 \mathrm{~b}, \mathrm{~L} 6+$, or $\mathrm{L} 6-$ neuron are shown with red and blue lines, respectively. Thick blue lines denote the thick straight axons.

\section{Intracellular labeling of pyramidal/spiny neurons and their local connections to CTNs}

In $500-\mu \mathrm{m}$-thick cortical slices containing retrogradely labeled CTNs, 11, 9, 29, and 41 pyramidal/spiny neurons were sampled in L2/3, L4, L5, and L6, respectively, for intracellular recording/ staining in the posteromedial barrel subfield of the rat S1 cortex. All the stained neurons were pyramidal neurons, except for four spiny stellate cells and one star pyramid of Lorente de Nó (1938) sampled in L4. We collected five pyramidal/spiny neurons from L2/3 and L4 and eight from L5 (Fig. $2 A-C$ ) that met the criteria for sufficient retrograde labeling and intracellular staining (see 


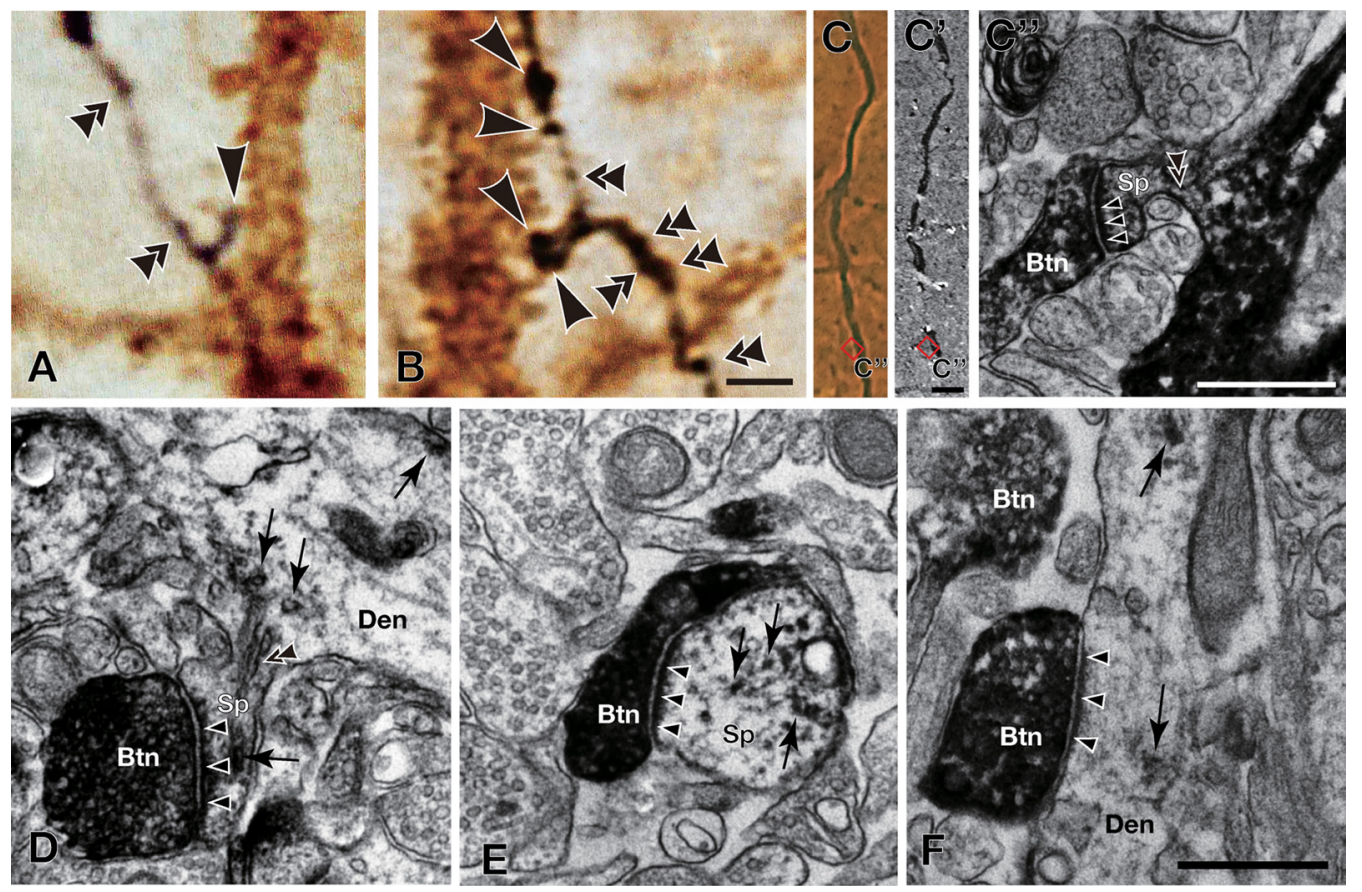

Figure 4. Analyses of axon boutons and synapses. $A, B$, Axonal processes of intracellularly labeled pyramidal neurons and dendritic processes are shown in black (nickel-enhanced DAB) and brown (DAB), respectively. Some axon boutons are closely apposed to CTN dendrites as indicated by single arrowheads. Other boutons that presumably have other targets than CTNs are indicated by double arrowheads. Boutons are indicated only when they are in the plane of focus. $\mathbf{C}-\boldsymbol{F}$, Electron microscopic observation of randomly selected apposed boutons revealed that $77 \%$ of the appositions formed synapses; arrowheads in C $\boldsymbol{F}$ indicate asymmetric synapses made between nickel-enhanced DAB-labeled boutons (Btn) and DAB-labeled dendritic spines (Sp in C-E) or dendritic shafts (Den in $\boldsymbol{F}$ ). Examples of DAB deposits are indicated by arrows. Double arrowheads in $\boldsymbol{C}^{\prime \prime}$ and $\boldsymbol{D}$ indicate spine necks that connect a spine head (Sp) with a dendritic shaft (Den). Samples for electron microscopy were obtained by the same method as described by Cho et al. (2004b), except that we used the anti-GFP antibody (2-5 $\mu \mathrm{g} / \mathrm{ml}$ ) as the primary antibody. Scale bars: (in $\boldsymbol{B}) \boldsymbol{A}, \boldsymbol{B}, 2 \mu \mathrm{m}$; (in $\boldsymbol{C} C_{,} \boldsymbol{C}^{\prime}, 5 \mu \mathrm{m} ; \boldsymbol{C}^{\prime}, 500 \mathrm{~nm}$; (in $\left.\boldsymbol{F}\right), \boldsymbol{D}-\boldsymbol{F}, 500 \mathrm{~nm}$.

also Materials and Methods). We also accumulated five each of GFP-positive and GFP-negative pyramidal neurons located in L6 (Fig. $2 D, E$ ). We further divided eight L5 neurons into three L5a neurons and five L5b neurons according to their cell body locations (Schubert et al., 2006). As a result, each of the L2/3, L5b, L6 GFP-positive (L6+), or L6 GFP-negative (L6-) pyramidal neuron groups examined in the present study was thus comprised of five pyramidal neurons and the L5a neuron group contained three pyramidal neurons. The L4 neuron group involved two pyramidal neurons, two spiny stellate cells, and one star pyramid. Finally, all the 28 neurons were located in barrel columns, but not in septal columns of the posteromedial barrel subfield.

L6- pyramidal neurons were different from thalamusprojecting L6+ neurons in several morphological and electrophysiological properties, and may represent a type of pyramidal neuron different from the CTN. All L6+ neurons showed tonic firing responses to a strong current injection, whereas four of the five L6- neurons displayed phasic firing responses. The fast hyperpolarizing afterpotentials of L6 + neurons were relatively deep and significantly different from those of L6- neurons (Table 3). Morphologically, L6+ neurons had narrow basal dendritic arbors and tufted apical dendrites that extended to L4, whereas L6- neurons had wide basal dendritic arbors and short apical dendrites that ended without entering L4. The axon collaterals of L6+ neurons took a direction toward the pia mater and entered L4 without spreading widely, while those of L6 - neurons mainly spread horizontally through L5/6 (Table 2; Fig. 3). Because these electrophysiological and morphological properties of L6- neurons were similar to those of L6 corticocortical neurons identified by single axon tracing (Zhang and Deschênes, 1997) or by the lack of retrograde labeling after massive injection of retrograde tracer into the thalamus (Brumberg et al., 2003; Mercer et al., 2005; Kumar and Ohana, 2008), at least a subset of L6- neurons were considered corticocortical neurons.

The local axon collaterals of the reconstructed pyramidal/ spiny neurons had many boutons, which were putative presynaptic structures. Some axon boutons of the pyramidal/spiny neurons were closely apposed to the dendrites of retrogradely labeled CTNs (hereafter called "apposed boutons"; Fig. 4A,B). The largest average number of apposed boutons per presynaptic neuron was observed for L6- neurons, followed by L6+, L5a, L5b, L4, and L2/3 neurons (Table 2), indicating that on average single L6 - neurons exert a stronger influence on CTNs than single neurons of any other pyramidal/spiny neuron group.

In a different set of electron-microscopic studies, we randomly chose 35 apposed boutons to examine whether each of them actually made synaptic contact with an immunolabeled postsynaptic structure. All the apposed boutons examined were electron-microscopically confirmed as presynaptic structures. Of them, 27 were in synaptic contact against GFP-immunopositive postsynaptic profile (Figs. $4 C-F)$, the rate $(77 \%$; 27/35) being consistent with previous reports (Markram et al., 1997; Kaneko et al., 2000; Cho et al., 2004b). The other eight apposed boutons were proved to be presynaptic structures with GFP-negative postsynaptic targets.

\section{Horizontal distribution of local connections onto CTNs}

To clarify the horizontal distribution of local connections in addition to the laminar distribution, we digitized the positions of apposed boutons in axons originating from intracellularly labeled pyramidal/spiny neurons in a three-dimensional space (Fig. 5). The distribution of apposed boutons in the horizontal 
plane perpendicular to the cortical columnar structures differed between the pyrami$\mathrm{dal} /$ spiny neuron groups; for example, in Figure 6, $A 1$ and $A 2$, L6+ and L4 neurons displayed much narrower distributions than L5 neurons shown in Figure $6 A 3$.

The "horizontal distance" between each apposed bouton and the cell body of its origin was normalized by measuring, after projection of the bouton and the cell body onto the L4/5 boundary plane to compensate for the effect of cortical curvature on the horizontal distance (Fig. $6 B)$. In Figure $6 C$, the horizontal distribution of the apposed boutons arising from each neuron was summarized in a relative frequency histogram showing a single peak (blue lines and histograms are sample distributions, and black lines are fitting curves for determining peak positions; see Materials and Methods). The apposed boutons of L4 and L6+ neurons showed peak positions closer to their cell bodies and narrower half widths than those of the other neuron groups. Differences in the peak distance and half width between L4 neuron group and L2/3, L5b, or L6 - group, or those between L6+ group and L2/3 or L6 - group showed statistical significance (Fig. $6 D, E$ ). These results suggest that L4 and L6+ neurons are more likely to project to nearby CTNs than are neurons of the other groups. In contrast, L6- neurons exhibited the most distant peak position and the broadest half width (Fig. 6D,E). Consistent with these findings, the averaged cumulative distributions of the L4 and L6+ neuron groups increased rapidly, whereas that of the L6- neuron group rose slowly as $x$ increased (Fig. $6 F$ ).

\section{Connections to apical and basal}

dendrites of CTNs

Since apical and basal dendrites may separately integrate their inputs and distinctly affect the output of a cortical pyramidal neuron (Mel, 2008; Sjöström et al.,

2008; Ledergerber and Larkum, 2010), we further tried to examine the difference between the horizontal distributions of boutons targeting the apical dendrites of CTNs and those targeting the basal dendrites. We first examined the histograms of frequency and relative frequency against the vertical location of apposed boutons (Fig. 7A). L2/3, L4, and L5a neurons allocated the most of their apposed boutons within L4/5, while L6+ and L6neurons distributed the majority of their apposed boutons in L6. L5b neurons dispersed their apposed boutons rather evenly in L4/5 or in L6. For further analyses, we compared the horizontal distributions of apposed boutons in L4/5 and those in L6 for each pyramidal/spiny neuron group, as the majority of apical or basal dendrites of L6 CTNs spread in L4/5 or L6, respectively (Fig. 1 B). In Figure $7 B$, the histograms show that L6 apposed boutons originating from a representative L4 spiny stellate cell were concentrated near the cell body (green), whereas its L4/5 boutons had the peak of the distribution at $\sim 200 \mu \mathrm{m}$ from the cell body (or-
Frontal view Side view

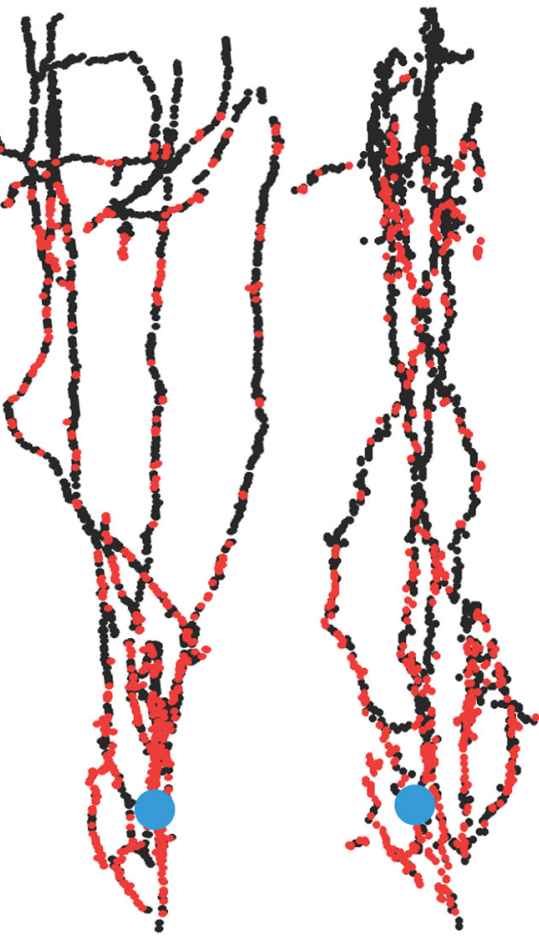

Top view
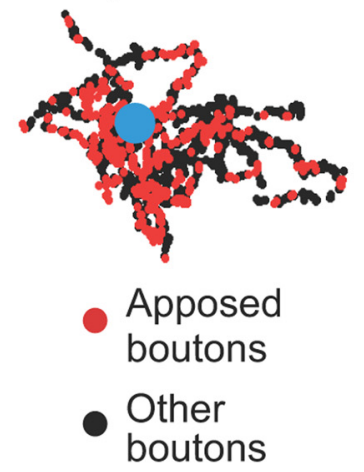

Cell body

Figure 5. Three-dimensional distribution of axon boutons. The axon boutons of an L6+ pyramidal neuron were plotted three-dimensionally, and shown in three different views.

ange). A similar distribution was observed in all subtypes of L4 pyramidal/spiny neurons and thus the average cumulative distribution of L6 apposed boutons arising from L4 pyramidal/spiny neurons was saturated at a clearly smaller $x$ than that of L4/5 apposed boutons (Figs. 7C). Significant differences between the peak positions of L4/5 and L6 apposed boutons were only found in the L 4 neuron group ( $p=0.0008$ by $t$ tests with Bonferroni correction, Fig. 7D), but not in the other neuron groups. This characteristic distribution of apposed boutons originating from L4 neurons was mainly ascribed to their axonal arborization. As shown in Figure 7E, the axon collaterals of L4 neurons were widespread in L2-5 but highly restricted in L6.

\section{Morphological estimation of local excitatory inputs to L6 CTNs}

We next reexamined the present data so that we could estimate inputs from a mass of neurons to CTN dendrites and obtain a 

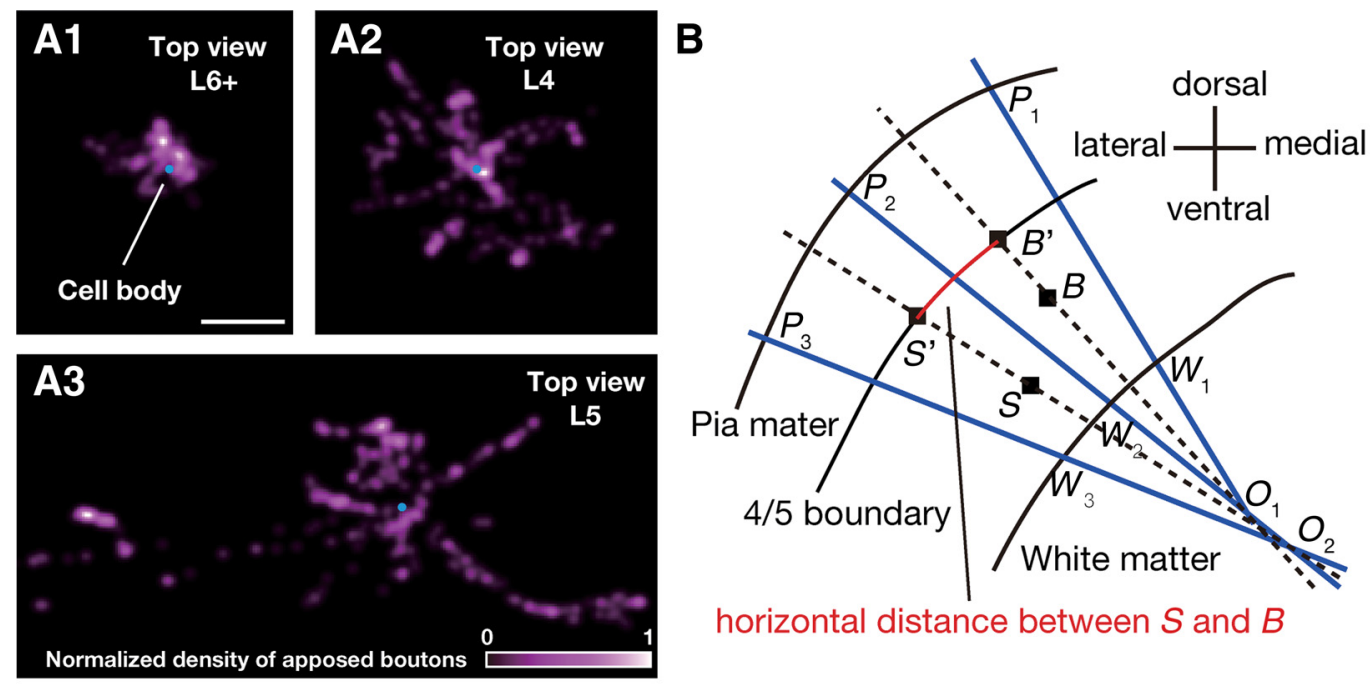

horizontal distance between $S$ and $B$

C1

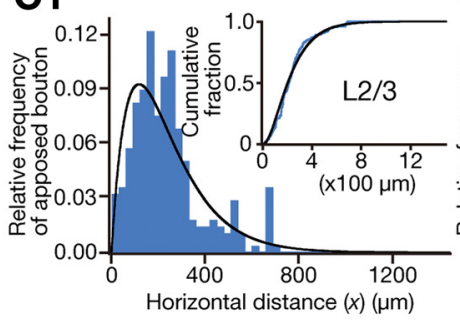

C4

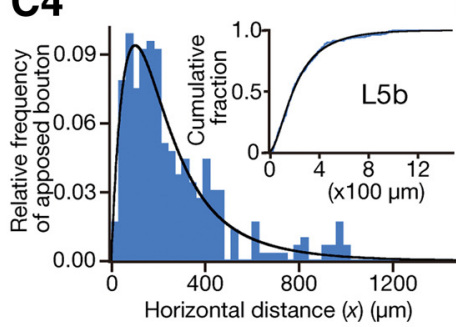

D

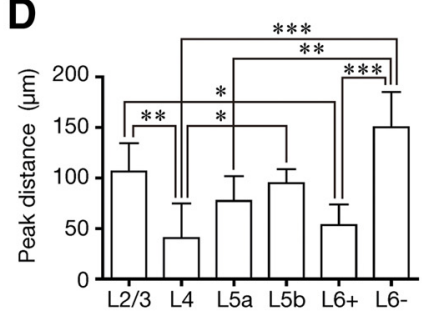

C2

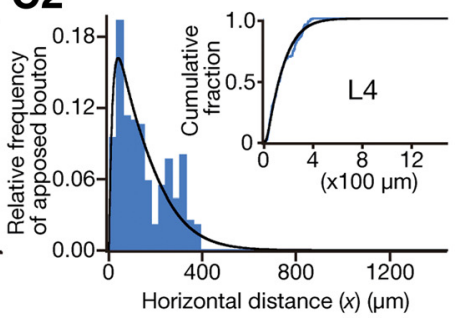

C5

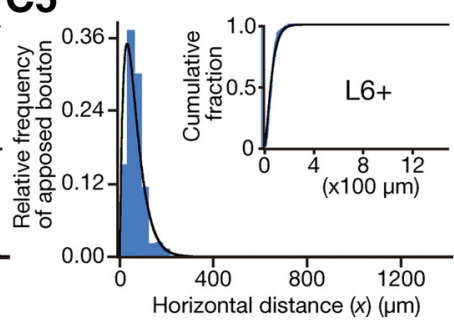

E

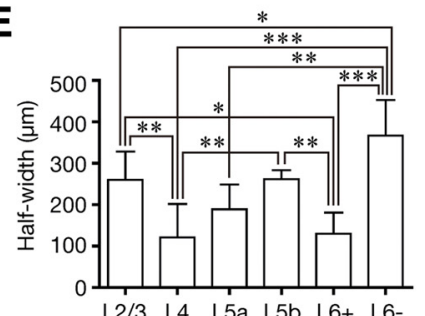

C3

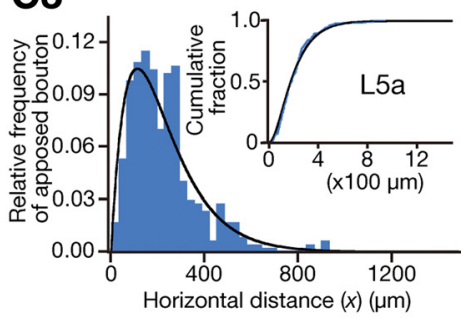

C6

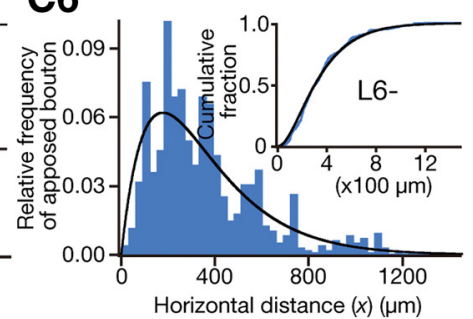

F

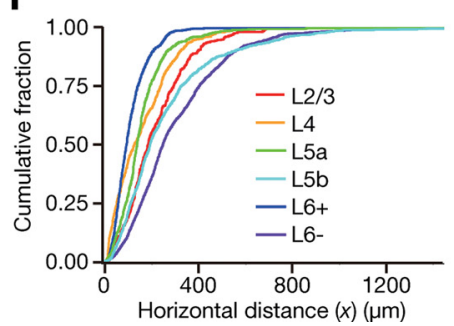

Figure 6. Horizontal distribution of apposed boutons. A1-3, The density map of apposed boutons in a horizontal plane (Fig. 5, the plane corresponding to "Top view") is shown after being smoothed by $2 \mathrm{D}$ convolution with a Gaussian kernel $(\sigma=4 \mu \mathrm{m}$; a comparable value with the interbouton interval) and normalized (bottom of $A 3)$. $\boldsymbol{B}$, We plotted the boundary of $L 4$ and $L 5$ ( $L 4 / 5$ boundary) and the directions of apical dendrites of corticothalamic neurons every $50 \mu \mathrm{m}$ (lines $P_{m} W_{m}$ ) and determined $O_{m}$ as the intersection of lines $P_{m} W_{m}$ and $P_{m+1} W_{m+1}$. These intersections were always located in the white matter because of the convexity of the rat cerebral cortex. The locations of the cell body and boutons were then projected onto $L 4 / 5$ boundary; for examples, $S$ was projected along line $\mathrm{SO}_{2}$ to $S^{\prime}$ and $B$ along line $B_{1}$ to $B^{\prime}$. Horizontal distance $x$ between $S$ and $B$ is to be measured as the distance between $S^{\prime}$ and $B^{\prime}$ along the $L 4 / 5$ boundary (red curve). Because the rat barrel cortex along the rostrocaudal axis is much flatter, no correction for rostrocaudal direction was performed. C1-6, Relative frequency histograms (blue histogram, bin size $=30 \mu \mathrm{m}$ ) and cumulative fractions (insets, blue lines, bin size $=1 \mu \mathrm{m}$ ) for the horizontal distance of apposed boutons originating from a representative cell in each layer. Each distribution was fitted with a mixture of gamma distributions (black lines). Most distributions were best fitted with a single gamma distribution in terms of the Bayesian information criterion. $\boldsymbol{D}, \boldsymbol{E})$, The peak position and the half width of the curves are compared between the neuron groups. $\boldsymbol{F}$, The cumulative fraction averaged within each neuron group (bin size $=1 \mu \mathrm{m}$ ). $S$ cale bar: (in $\boldsymbol{A 1}$ ) $\boldsymbol{A} 1-\mathbf{3}, 100 \mu \mathrm{m}$. Each bar and error bar in $\boldsymbol{D}, \boldsymbol{E}$ represents the mean and SD, respectively. ${ }^{*} p<0.05 ;{ }^{* *} p<0.01 ;{ }^{* * *} p<0.001$ by Peritz's $F$ test.

morphological input map that is comparable to the maps observed in previous photostimulation studies on L6 pyramidal neurons (Briggs and Callaway, 2001; Zarrinpar and Callaway, 2006; Llano and Sherman, 2009; Lam and Sherman, 2010; Hooks et al., 2011). For this reexamination, we made the following three suppositions: (1) The density of CTN dendrites is uniform at a given cortical depth, (2) the distribution and density of cell bodies of pyramidal/spiny neurons are horizontally constant at a given cortical depth, and (3) as a group, pyramidal/spiny neurons at a given cortical depth distribute their apposed boutons to 
A1

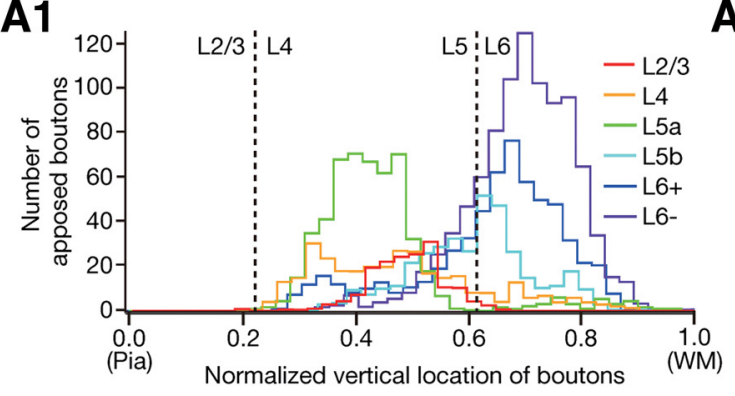

B1

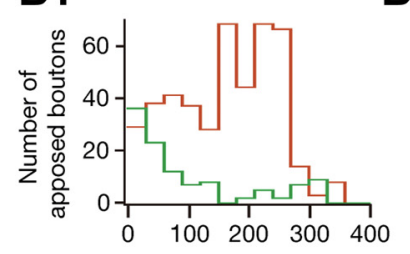

B2

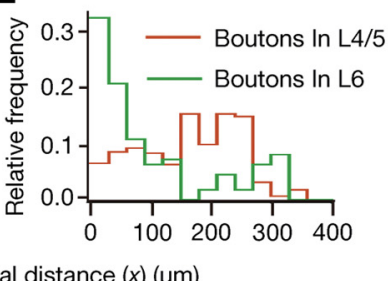

Horizontal distance $(x)(\mu \mathrm{m})$
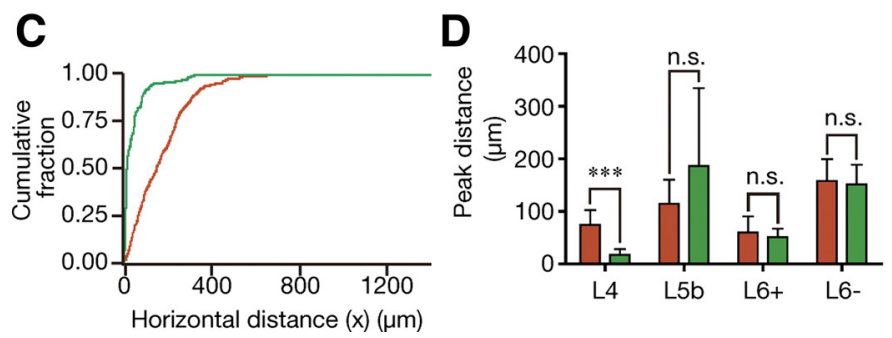

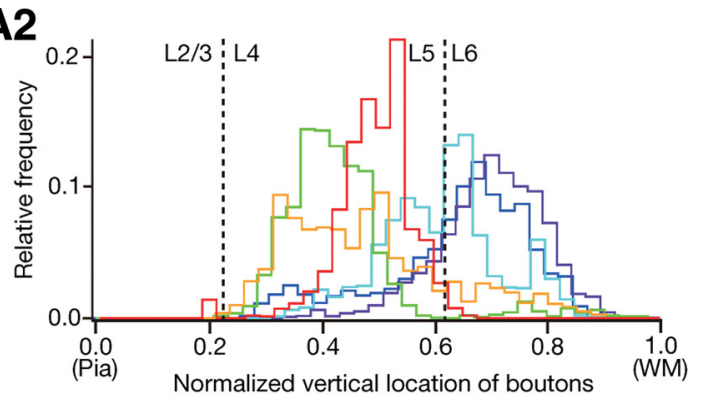

E

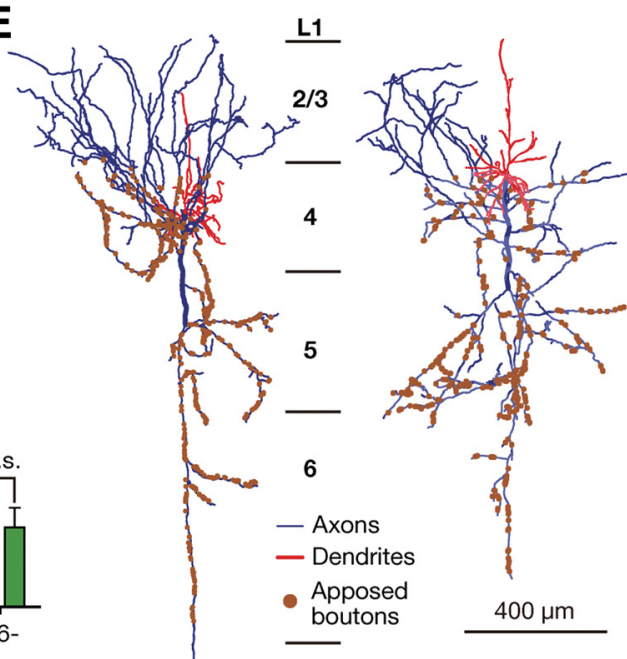

Figure 7. Horizontal distribution of apposed boutons onto the apical and basal dendrites of CTNs. $\boldsymbol{A}$, Frequency (A1) and relative frequency (A2) histograms of apposed boutons against the vertical axis of the cerebral cortex. The vertical locations of boutons are expressed in a linear normalized scale in which the pia mater is set to 0.0 (Pia) and the white matter border is to 1.0 (WM). Dashed lines show the boundaries between $L 2 / 3$ and $L 4$ or between $L 5$ and $L 6$. B, Frequency (B1) and relative frequency (B2) histograms of apposed boutons originating from a representative $L 4$ neuron (bin size $=30 \mu \mathrm{m}$ ). We divided apposed boutons into boutons in $L / 5$ (orange) and those in $L 6$ (green). The main targets of $L 4 / 5$ and $L 6$ apposed boutons were the apical and basal dendrites of CTNs, respectively. C, The averaged cumulative fractions of five $L 4$ neurons (bin size $=1 \mu \mathrm{m}$ ). D. The peak positions of the distributions of $L 4 / 5$ (orange) and $L 6$ apposed boutons (green) in each neuron group. The peaks were determined by fitting a mixture of gamma distributions as described in Figure 6 , and all distributions were best fitted with a single gamma distribution by the Bayesian information criterion. Because all the $L 2 / 3$ neurons and two of three $L 5$ a neurons have $<5 \%$ of their apposed boutons in $L 6$, we did not perform a similar analysis for $L 2 / 3$ and $L 5$ a neuron groups. Only $L 4$ neurons showed a significant difference between peak positions of $L 4 / 5$ and $L 6$ apposed boutons. Each bar and error bar represents the mean and SD ( $N=5$ neurons per group), respectively. n.s., Not significant. ${ }^{* *} p<0.001$ by two-tailed $t$ test with Bonferroni correction. $\boldsymbol{E}$, Representative reconstructions of $L 4$ spiny stellate cells (left) and star pyramids (right). Note that the axons in L6 go straight down and have only a few branches in $L 6$.

CTNs isotropically but as a function of horizontal distance $x$. From the original experimental data (Fig. 6), we obtained the number of apposed boutons arising from a pyramidal/spiny neuron as a function of horizontal distance $x$ (an average pyramidal/spiny neuron shown as the black neuron in Fig. $8 \mathrm{~A}$, top). Within a neuron group, when a neuron on average sends a certain amount of axon boutons onto CTN dendrites in a given volume, depicted as the green rectangular prism in Figure $8 \mathrm{~A}$ (middle), these CTN dendrites are expected to receive the same amount of axon boutons from each neuron located at the same distance from them in all directions (Fig. $8 \mathrm{~A}$, bottom) according to the above three suppositions. Therefore, as shown in Figure $8 B$, we cut a slice to see a two-dimensional morphological input map; in other words, we obtained $i(x, y)$, which indicates the number of apposed boutons on CTN dendrites in a slender green square prism $\left(1 \times 1 \mu \mathrm{m}^{2}\right.$ base $)$ by neurons within a cube located at horizontal distance $x$ and normalized vertical location $y$.

The two-dimensional plot of $i(x, y)$ in Figure $8 C$ revealed that the highest $i(x, y)$ was observed at L 4 and the second highest was found at L6a. The ranges of $x$ with high $i(x, y)$ showing statistical significance were $x \leq 40 \mu \mathrm{m}$ in L4 and $x \leq 60 \mu \mathrm{m}$ in L6a (Fig. $8 C$, black lines). This result suggests that L4 and L6a pyramidal/spiny neurons are important local sources of inputs to CTNs and that at least a portion of L4 neurons have a strong impact on the CTNs located in a narrow region underneath these L4 neurons.

Since apposed boutons of L4 neurons targeting the basal dendrites of CTNs were distributed in a very narrow region just below these L4 neurons as shown in Figure 7, the focused L4-toCTN connections were most likely to be formed between descending axon fibers of L4 neurons and the basal dendrites of CTNs. To evaluate the contribution of these boutons, we recalculated, or simulated, $i(x, y)$ without basal dendrite-targeting L6 boutons originating from L4 neurons. The plot of the simulated $i(x, y)$ in Figure $8 D$ showed that inputs from L4 were greatly decreased compared with those found in Figure $8 C$, and that the domain associated with statistically significant connections was only found in L6a (Fig. 8D, black line). This result suggests that the strong, focused L4-to-CTN connections are mainly due to the basal dendrite-targeting boutons.

We further calculated inputs from a cylindrical mass of neurons and obtained $I_{\mathrm{L}}\left[x_{1}, x_{2}\right]$ that represents the number of apposed boutons on CTN dendrites in a slender prism $\left(1 \times 1 \mu \mathrm{m}^{2}\right.$ base) by the neurons that are classified into each pyramidal/spiny neuron group ( $\mathrm{L}=\mathrm{L} 2 / 3, \mathrm{~L} 4, \mathrm{~L} 5 \mathrm{a}, \mathrm{L} 5 \mathrm{~b}, \mathrm{~L} 6+$, or L6-) and located in the hollow cylinder whose internal and external radii are $x_{1}$ and 

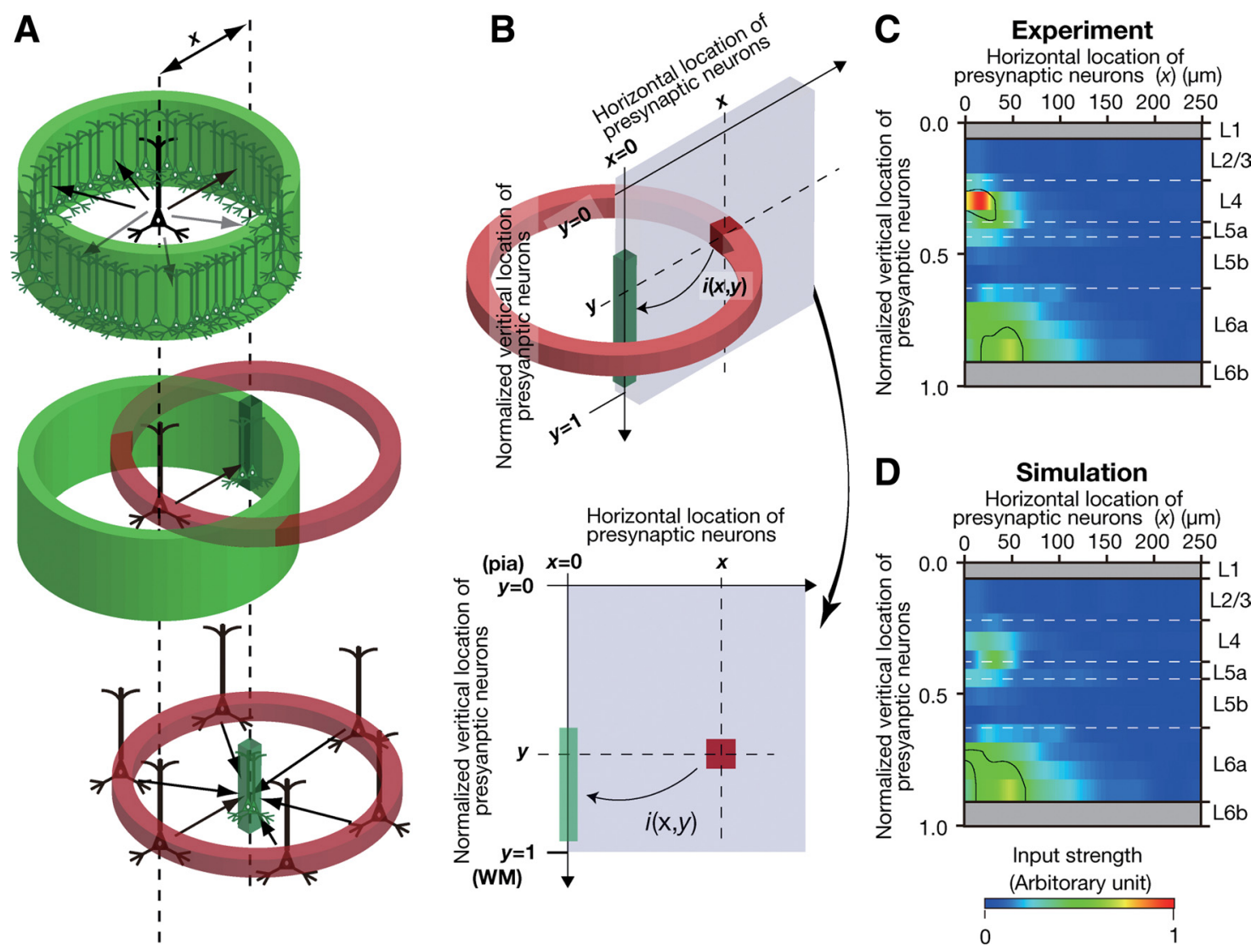

Figure 8. Estimation of input from pyramidal/spiny neurons in a cube to CTN dendrites. $A$, Reexamination of the data under the three suppositions described in the text. An average neuron in each pyramidal/spiny neuron group distributed its apposed boutons isotropically to CTN dendrites located at a horizontal distance $x$ (green cylinder, top). The red cylinder (middle) represents another hollow cylinder filled with pyramidal/spiny neurons around a green prism. CTN dendrites in the central prism would then receive the same amount of projections from each average neuron located at the same distance from these dendrites in all directions (bottom). $\boldsymbol{B}$, As shown on top, $i(x, y)$ represents the number of apposed boutons projected to CTN dendrites in the prism by neurons in a cube located at $(x, y)$. The scheme of two-dimensional input map is shown on bottom. $C, i(x, y)$ is displayed in the $x-y$ plane (smoothed with Gaussian kernel; $\sigma=10 \mu \mathrm{m}$ for $x$ ). Color code shows the magnitude of $i(x, y)$ in normalized value (maximum $=1)$, and regions encircled by black borders show significantly high $i(x, y)(>$ mean $+2 S D$; calculated within the range of $x=0-200 \mu \mathrm{m})$. $\boldsymbol{D}$, Simulated $i(x, y)$ without basal dendrite-targeting $L 6$ boutons originating from $L 4$ neurons. Magnitude of $i(x, y)$ in $\boldsymbol{D}$ is normalized with the maximum value in $\boldsymbol{C}$. Note that the signal in $L 4$ is remarkably reduced.

$x_{2}$, respectively (Fig. 9A). Considering the size of the barrel in the posteromedial barrel subfield ( $<200 \mu \mathrm{m}$ in radius) (Welker and Woolsey, 1974; Fox, 2008) and the maximum horizontal distance found in our samples $(1492 \mu \mathrm{m})$, we compared $I[0,200]$ and $I[200,1500]$ between the five pyramidal/spiny neuron groups. $I_{\mathrm{L} 6+}[0,200]$ was higher than the $I_{\mathrm{L}}[0,200]$ of any other neuron group, while $I_{\mathrm{L} 6-}[200,1500]$ displayed larger value than any other $I_{\mathrm{L}}[200,1500]$. This suggests that CTNs themselves are the most important nearby/columnar source of connections, whereas L6 corticocortical neurons are the most crucial distant/ extracolumnar source.

\section{Correlative location of L4 axons and CTN dendritic bundles}

The horizontally focused L4-to-CTN connection (Fig. 8) may be organized with certain vertical structures in the cerebral cortex, such as apical dendritic bundles of CTNs. The bundles typically consisted of 2-5 apical dendrites and their interbundle distance was $56 \pm 14 \mu \mathrm{m}$ (mean $\pm \mathrm{SD}, N=7$ slices). $I_{\mathrm{L} 4}[0,28]$ and $I_{\mathrm{L} 6+}[0$, 28 ] were significantly higher than those of the other neuron groups (Fig. 9D). This result confirms the importance of L4 neurons as a source of inputs to CTNs within a narrow horizontal range. We further examined the relationship of descending thick axons of L4 neurons with CTN dendritic bundles, compared with those of L2/3 neurons. The thick axons of L4 neurons approached
CTN dendritic bundles in the middle of L5 and descended in close association with CTN bundles (Fig. $9 F$ ), whereas those of L2/3 neurons descended straight to the white matter and did not come into contact with CTN bundles (Fig. 9E). Consistently, the thick axons of L4 neurons descended at a closer distance $(\sim 7$ $\mu \mathrm{m})$ to the center of the nearest dendritic bundle than axons originating from L2/3 neurons $(p=0.045$ by two-tailed $t$ test; Fig. $9 G$ ). As the diameter of CTN dendritic bundles was $\sim 10 \mu \mathrm{m}$, the thick axons of L4 neurons ran alongside the bundles (Fig. $9 F$ ).

\section{Discussion}

Here, we estimated local excitatory inputs to CTNs (Figs. 8, 9) on the basis of the distribution of apposed boutons of cortical pyramidal/spiny neurons to CTNs (Table 2; Fig. 6). L6 CTNs themselves and L4 neurons were the important nearby sources of connections to CTNs, whereas L6 corticocortical neurons were the main distant source within the local $(<1500 \mu \mathrm{m})$ connections. We further found that CTNs received strong and focused inputs from L4 neurons just above them and that this focused L4-to-CTN connectivity was formed between descending axon fibers of L4 neurons and the basal dendrites of CTNs. (Figs. 7, $8 D$ ). These results illustrate which excitatory neurons of the S1 cortical column send information through L6 CTNs to the thalamic compartment corresponding to the column. 


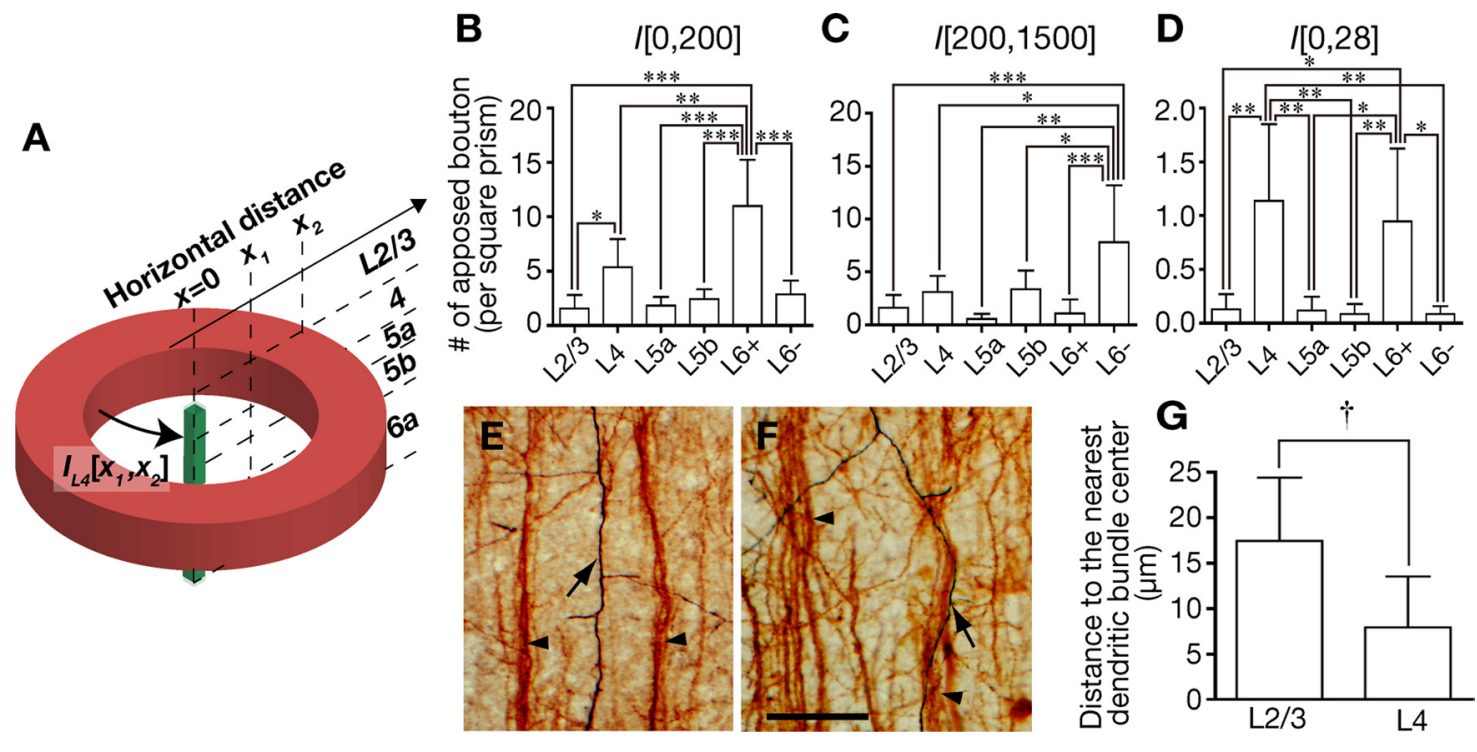

Figure 9. Horizontal organization of local excitatory inputs to CTNs. $A$, An example of $I_{L}\left[X_{1}, X_{2}\right]$. As the scheme shows, $I_{L}\left[X_{1}, X_{2}\right]$ represents the number of apposed boutons on CTN dendrites in the central slender prism $\left(1 \times 1 \mu \mathrm{m}^{2}\right.$ base) by the neurons that are classified into each pyramidal/spiny neuron group $(\mathrm{L}=\mathrm{L} 2 / 3, \mathrm{~L} 4, \mathrm{~L} \mathrm{~L} \mathrm{a}, \mathrm{L} \mathrm{Lb}, \mathrm{L} 6+$, or $\mathrm{L} 6-)$ and located in the hollow cylinder whose internal and external radii are $x_{1}$ and $x_{2}$, respectively. $\boldsymbol{B}-\boldsymbol{D}$, Inputs from neurons located at $x=0-200 \mu \mathrm{m}(\boldsymbol{B}), x=200-1500 \mu \mathrm{m}(\boldsymbol{C})$, and $x=0-28 \mu \mathrm{m}(\boldsymbol{D})$. $\boldsymbol{E}, \boldsymbol{F}$, Descending thick axons of a representative $L 2 / 3$ neuron $(\boldsymbol{E})$ and $L 4$ neuron $(\boldsymbol{F})$ are indicated by arrows and dendritic bundles of CTNs are indicated by arrowheads. Note that the axon of the $L 4$ neuron changes course and approaches a CTN dendritic bundle in the middle of $L 5$ and descends along the bundle. $G$, The minimal distance between the descending axon and the center of the nearest apical dendritic bundle showed that the descending axons of $L 4$ neurons ran at closer range to the dendritic bundle than those of $\mathrm{L} 2 / 3$ neurons. Scale bar, (in $\boldsymbol{F}$ ) $\boldsymbol{E}, \boldsymbol{F}, 50 \mu \mathrm{m}$. Each bar and error bar represents the mean and SD, respectively. ${ }^{*} p<0.05 ;{ }^{* *} p<0.01 ;{ }^{* * *} p<0.001$ by Peritz's $F$ test. $\dagger p<0.05$ by two-tailed $t$ test.

Strong local excitatory inputs to L6 CTNs from their own layer were found in previous studies using laser-scanning photostimulation by glutamate uncaging (Zarrinpar and Callaway, 2006; Llano and Sherman, 2009; Lam and Sherman, 2010; Hooks et al., 2011). Because photostimulation with a resolution of $50-75 \mu \mathrm{m}$ probably would activate several CTNs simultaneously (Hooks et al., 2011), large EPSPs might be evoked in the recorded neuron through dense nearby connections between CTNs. Similar results were obtained by our morphological estimation of inputs to CTNs from neurons in a cube (Fig. $8 \mathrm{C}$ ) or in a cylindrical volume (Fig. 9D).

The present results further suggest that a small population of L4 neurons located just above a CTN appear to be a main source of connections to this CTN (Fig. 8). Interestingly, a photostimulation study reported a case of strong L4 inputs to a putative L6 CTN [Zarrinpar and Callaway (2006), their Fig. 4A]. Furthermore, a recent multiple whole-cell recording study of the mouse barrel cortex has reported cases of L4-to-L6 connections (3/93 pairs) and has also shown that EPSP amplitudes of these connections are sometimes much larger $(0.17,0.96$, and $5.67 \mathrm{mV})$ than the typical EPSP amplitude in postsynaptic L6 neurons $(\sim 0.2 \mathrm{mV})$ (Lefort et al., 2009). These large EPSP amplitudes of L4-to-L6 connections might be well represented by the strong, focused L4-to-CTN connection revealed in the present study (Fig. 8C).

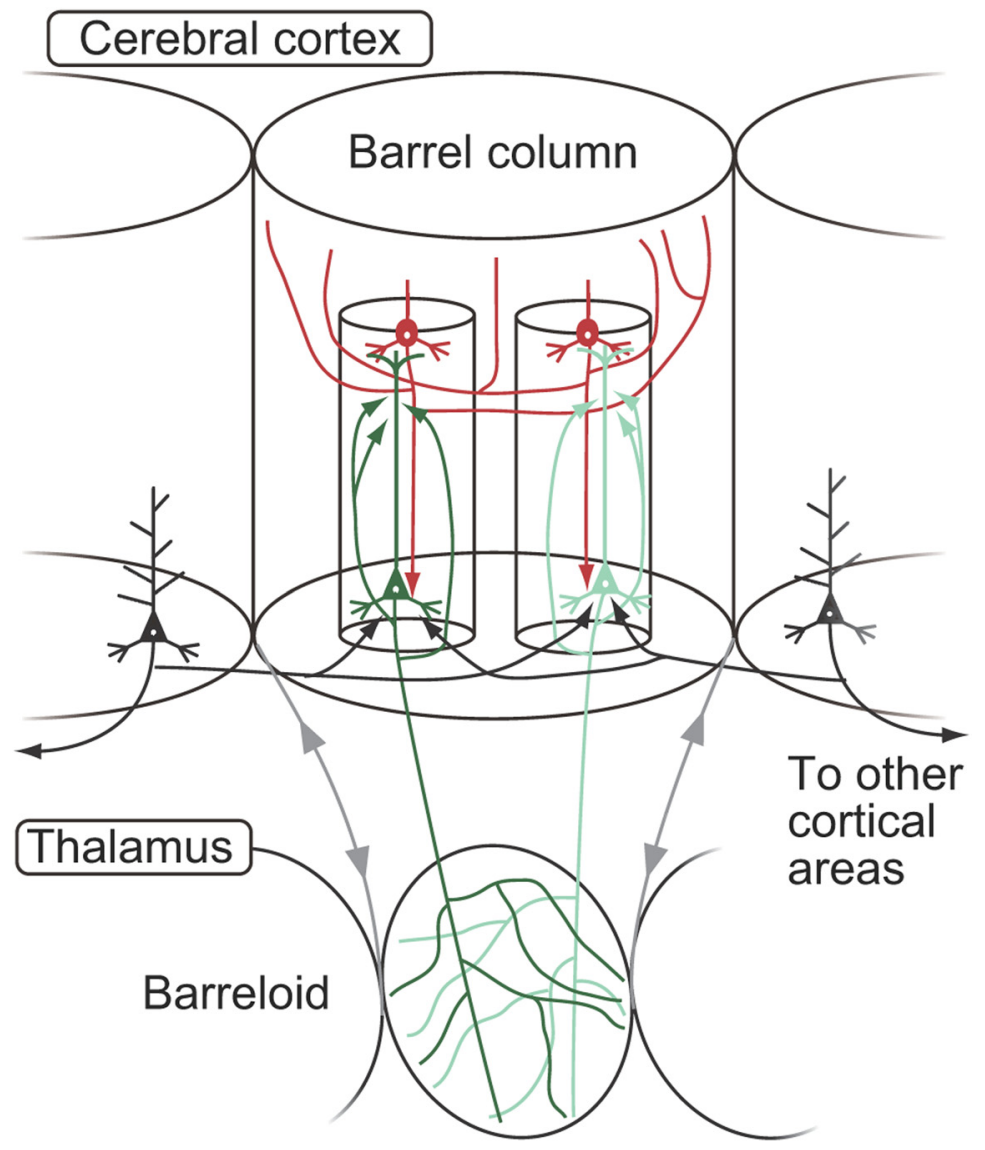

Figure 10. Anatomical organization of local excitatory connections to L6CTNs and its relationship to thalamic barreloid. Within a barrel column, the L6 CTNs receive strong, focused connections from L4 neurons located just above them (red). L6 CTNs have dense recurrent connections of a subcolumnar size within themselves (green), whereas $L 6$ corticocortical neurons provide CTNs with a considerable amount of horizontal connection beyond the barrel column (black). The projecting axons of L6 CTNs spread out in the corresponding thalamic compartment (barreloid) and thus show a multitude of overlaps within the barreloid. 
Although strong L4-to-L6 connections were found in a few cases in photostimulation and multiple whole-cell recording studies (Zarrinpar and Callaway, 2006; Lefort et al., 2009; Hooks et al., 2011), these previous studies generally showed infrequency of L4-to-L6 excitatory connections (Briggs and Callaway, 2001; Zarrinpar and Callaway, 2006; Lefort et al., 2009; Llano and Sherman, 2009; Lam and Sherman, 2010; Hooks et al., 2011). This seems contradictory to the present findings that strong morphological connections were constantly found from L4 neurons to CTNs. This contradiction might be explained by differences in animal age, species, or cortical area examined, but technical differences should be considered when comparing present and previous methods. We recorded neurons at a deep position from the slice cut surface and plotted the apposed boutons throughout the thickness $(500 \mu \mathrm{m})$ of the cortical slices. This might be helpful in observing the focused L4-to-CTN connections. On the other hand, in laser-scanning photostimulation and in whole-cell recordings, because neurons near the slice cut surface are preferentially stimulated by laser beams and recorded by patch pipettes, a vertically aligned, focused connection could be found only when the focused connection was set appropriately near the surface of a slice. This may be one of the reasons why strong L4-to-CTN connections have been reported only infrequently by previous photostimulation or multiple whole-cell recording studies.

The presence of strong, focused L4-to-CTN connections raises the possibility that there are functional substructures in a barrel column. In the measurement of $i(x, y)$, the L4 neurons forming strong connections to a portion of CTN dendrites were located within 40 $\mu \mathrm{m}$ in horizontal distance from these CTN dendrites (Figs. 8C, 9D). Recent physiological studies have pointed out that single barrels include several neuronal clusters ( $\sim 100 \mu \mathrm{m}$ in diameter) that contain neurons showing similar preferences for the direction of whisker deflection, suggesting that barrel columns are divided into functional substructures (Bruno et al., 2003; Andermann and Moore, 2006) such as orientation columns in the ocular dominance column of the cat and monkey primary visual cortex (Mountcastle, 1997). One of the potential anatomical substrates of these functional substructures in the barrel column is dendritic bundles, which are commonly found in the mammalian neocortex (Rockland and Ichinohe, 2004). Visualizing CTN dendrites, we observed that CTNs formed apical dendritic bundles (Fig. 9E,F) and that the interbundle interval was $56 \pm 14 \mu \mathrm{m}$ (mean $\pm \mathrm{SD}$ ). Interestingly, this interval was very close to that of dendritic bundles formed by L5 pyramidal neurons in the rat $\mathrm{S} 1$ cortex $[\sim 50 \mu \mathrm{m}$ in the study by Feldman and Peters (1974) and $49 \pm 16 \mu \mathrm{m}$ in the study by Skoglund et al. (2004)]. More interestingly, the thick axons of L4 neurons descended in close proximity with CTN dendritic bundles (Fig. 9F, $G$ ), suggesting that L4 neurons around the CTN dendritic bundle focus their descending axons on CTNs forming the dendritic bundle. Because more than half of the dendritic length of CTNs $(62.1 \pm 8.2 \%$; measured from the present intracellularly labeled samples) was included within a $56 \mu \mathrm{m}$ radius cylinder around an apical dendritic shaft, both axons of L4 neurons and dendrites of L6 CTNs are arranged in a subcolumnar structure around CTN dendritic bundles.

Previous studies have shown that inactivation of the primary visual (Przybyszewski et al., 2000), auditory (Yan and Suga, 1996), or somatosensory (Yuan et al., 1986) cortices generally decreases thalamic responses to sensory stimuli (Alitto and Usrey, 2003). A recent study has further reported that activation of the barrel column enhances the sensory responses of relay neurons in the corresponding thalamic compartment, or barreloid (Temereanca and Simons, 2004). L6 CTN activation in a barrel column thus has an excitatory/ facilitatory influence on the activity of thalamic relay neurons, which transfer peripheral information to the cerebral cortex. The facili- tatory cortical control of thalamic activity by a single L6 CTN presumably spreads beyond a single barreloid, because a single L6 CTN in a barrel column spreads its axons throughout the corresponding barreloid (Bourassa et al., 1995) and because the dendrites of barreloid neurons extend into surrounding barreloids [33\% on average (Varga et al., 2002)]. Together with these structural and functional properties of CTNs, the local excitatory connections revealed in the present study suggest how finely the barrel column controls the activity of relay neurons in the corresponding barreloid and its surrounding structures (Fig. 10). In recent in vivo juxtacellular recordings and whole-cell recordings, it has been revealed that a single whisker deflection activates only a small fraction of L4 neurons (Brecht and Sakmann, 2002; de Kock et al., 2007), which are most likely organized into subcolumnar structures (Bruno et al., 2003; Andermann and Moore, 2006). When L4 neurons in a subcolumnar structure are activated, a limited number of CTNs therein might be activated via focused L4-to-CTN connections. Because a CTN at least innervates the whole extent of the corresponding barreloid (Bourassa et al., 1995; Varga et al., 2002), the subcolumnar structures might provide thalamic relay neurons with an additive or summative enhancement mechanism. In other words, when CTNs in several subcolumnar structures are activated in a barrel column, the activity of relay neurons in the corresponding barreloid might be facilitated in a finely additive manner that depends on the number of subcolumnar structures containing activated CTNs. With this additive mechanism, even on a weak, limited sensory input, the barrel cortex could provide a commensurate strength of excitatory/facilitatory feedback to all relay neurons in the corresponding barreloid, and finely control the thalamic activity to efficiently transfer information from the corresponding whisker to the cortex.

In conclusion, we have shown a detailed map of local excitatory inputs to L6 CTNs based on the morphological data. The data indicate that L4 pyramidal/spiny neurons have an important role in shaping the cortical modulation of thalamic relay neurons through CTNs. To examine whether local connectivity actually functions as discussed above, it will be of primary importance to explore the dynamics of neurons in the thalamocortical reciprocal circuit in alert animals.

\section{References}

Alitto HJ, Usrey WM (2003) Corticothalamic feedback and sensory processing. Curr Opin Neurobiol 13:440-445.

Andermann ML, Moore CI (2006) A somatotopic map of vibrissa motion direction within a barrel column. Nat Neurosci 9:543-551.

Bourassa J, Pinault D, Deschênes M (1995) Corticothalamic projections from the cortical barrel field to the somatosensory thalamus in rats: a single-fibre study using biocytin as an anterograde tracer. Eur J Neurosci 7:19-30.

Brecht M, Sakmann B (2002) Dynamic representation of whisker deflection by synaptic potentials in spiny stellate and pyramidal cells in the barrels and septa of layer 4 rat somatosensory cortex. J Physiol 543:49-70.

Briggs F, Callaway EM (2001) Layer-specific input to distinct cell types in layer 6 of monkey primary visual cortex. J Neurosci 21:3600-3608.

Brumberg JC, Hamzei-Sichani F, Yuste R (2003) Morphological and physiological characterization of layer VI corticofugal neurons of mouse primary visual cortex. J Neurophysiol 89:2854-2867.

Bruno RM, Khatri V, Land PW, Simons DJ (2003) Thalamocortical angular tuning domains within individual barrels of rat somatosensory cortex. J Neurosci 23:9565-9574.

Cho RH, Segawa S, Mizuno A, Kaneko T (2004a) Intracellularly labeled pyramidal neurons in the cortical areas projecting to the spinal cord. I. Electrophysiological properties of pyramidal neurons. Neurosci Res 50:381-394.

Cho RH, Segawa S, Okamoto K, Mizuno A, Kaneko T (2004b) Intracellularly labeled pyramidal neurons in the cortical areas projecting to the spinal cord. II. Intra- and juxta-columnar projection of pyramidal neurons to corticospinal neurons. Neurosci Res 50:395-410. 
de Kock CP, Bruno RM, Spors H, Sakmann B (2007) Layer- and cell-typespecific suprathreshold stimulus representation in rat primary somatosensory cortex. J Physiol 581:139-154.

Deschênes M, Veinante P, Zhang ZW (1998) The organization of corticothalamic projections: reciprocity versus parity. Brain Res Brain Res Rev $28: 286-308$

Douglas R, Markram H, Martin K (2004) Neocortex. In: The synaptic organization of the brain, Ed 5. (Sherherd GM., ed), pp 499-558. New York: Oxford UP.

Feldman ML, Peters A (1974) A study of barrels and pyramidal dendritic clusters in the cerebral cortex. Brain Res 77:55-76.

Fox K (2008) Barrel cortex. New York: Cambridge UP.

Furuta T, Kaneko T, Deschênes M (2009) Septal neurons in barrel cortex derive their receptive field input from the lemniscal pathway. J Neurosci 29:4089-4095.

Harper JF (1984) Peritz' F test: basic program of a robust multiple comparison test for statistical analysis of all differences among group means. Comput Biol Med 14:437-445.

Hioki H, Kameda H, Nakamura H, Okunomiya T, Ohira K, Nakamura K, Kuroda M, Furuta T, Kaneko T (2007) Efficient gene transduction of neurons by lentivirus with enhanced neuron-specific promoters. Gene Ther 14:872-882.

Hooks BM, Hires SA, Zhang YX, Huber D, Petreanu L, Svoboda K, Shepherd GM (2011) Laminar analysis of excitatory local circuits in vibrissal motor and sensory cortical areas. PLoS Biol 9: e1000572.

Howard CV, Reed MG (1998) Unbiased stereology: three-dimensional measurement in microscopy. Oxford: Bios Scientific Publishers.

Jones EG (1984) Laminar distribution of cortical efferent cells. In: Cellular components of cerebral cortex (Peters A, Jones EG, eds), pp 521-553. New York: Plenum.

Kameda H, Furuta T, Matsuda W, Ohira K, Nakamura K, Hioki H, Kaneko T (2008) Targeting green fluorescent protein to dendritic membrane in central neurons. Neurosci Res 61:79-91.

Kaneko T, Kang Y, Mizuno N (1995) Glutaminase-positive and glutaminasenegative pyramidal cells in layer VI of the primary motor and somatosensory cortices: a combined analysis by intracellular staining and immunocytochemistry in the rat. J Neurosci 15:8362-8377.

Kaneko T, Cho R, Li Y, Nomura S, Mizuno N (2000) Predominant information transfer from layer III pyramidal neurons to corticospinal neurons. J Comp Neurol 423:52-65.

Killackey HP, Sherman SM (2003) Corticothalamic projections from the rat primary somatosensory cortex. J Neurosci 23:7381-7384.

Kumar P, Ohana O (2008) Inter- and intralaminar subcircuits of excitatory and inhibitory neurons in layer 6 a of the rat barrel cortex. J Neurophysiol 100:1909-1922.

Kuramoto E, Fujiyama F, Unzai T, Nakamura K, Hioki H, Furuta T, Shigemoto R, Ferraguti F, Kaneko T (2007) Metabotropic glutamate receptor 4-immunopositive terminals of medium-sized spiny neurons selectively form synapses with cholinergic interneurons in the rat neostriatum. J Comp Neurol 500:908-922.

Kuramoto E, Furuta T, Nakamura KC, Unzai T, Hioki H, Kaneko T (2009) Two types of thalamocortical projections from the motor thalamic nuclei of the rat: a single neuron-tracing study using viral vectors. Cereb Cortex 19:2065-2077.

Lam YW, Sherman SM (2010) Functional organization of the somatosensory cortical layer 6 feedback to the thalamus. Cereb Cortex 20:13-24.

Ledergerber D, Larkum ME (2010) Properties of layer 6 pyramidal neuron apical dendrites. J Neurosci 30:13031-13044.

Lefort S, Tomm C, Floyd Sarria JC, Petersen CC (2009) The excitatory neuronal network of the $\mathrm{C} 2$ barrel column in mouse primary somatosensory cortex. Neuron 61:301-316.

Llano DA, Sherman SM (2009) Differences in intrinsic properties and local network connectivity of identified layer 5 and layer 6 adult mouse auditory corticothalamic neurons support a dual corticothalamic projection hypothesis. Cereb Cortex 19:2810-2826.

Lorente de Nó R (1938) Architectonics and the structure of the cerebral cortex. In: Physiology of the nervous system (Fulton JF, ed), pp 291-330. New York: Oxford UP.

Markram H, Lubke J, Frotscher M, Roth A, Sakmann B (1997) Physiology and anatomy of synaptic connections between thick tufted pyramidal neurones in the developing rat neocortex. J Physiol 500:409-440.

Mel BW (2008) Why have dendrites? A computational perspective. In: Den- drites, Ed 2. (Stuart G, Spruston N, Häusser M, eds), pp 421-440. New York: Oxford UP.

Mercer A, West DC, Morris OT, Kirchhecker S, Kerkhoff JE, Thomson AM (2005) Excitatory connections made by presynaptic cortico-cortical pyramidal cells in layer 6 of the neocortex. Cereb Cortex 15:1485-1496.

Mountcastle VB (1997) The columnar organization of the neocortex. Brain 120:701-722.

Nakamura K, Watakabe A, Hioki H, Fujiyama F, Tanaka Y, Yamamori T, Kaneko T (2007) Transiently increased colocalization of vesicular glutamate transporters 1 and 2 at single axon terminals during postnatal development of mouse neocortex: a quantitative analysis with correlation coefficient. Eur J Neurosci 26:3054-3067.

Nakamura KC, Kameda H, Koshimizu Y, Yanagawa Y, Kaneko T (2008) Production and histological application of affinity-purified antibodies to heatdenatured green fluorescent protein. J Histochem Cytochem 56:647-657.

Przybyszewski AW, Gaska JP, Foote W, Pollen DA (2000) Striate cortex increases contrast gain of macaque LGN neurons. Vis Neurosci 17:485-494.

Rockland KS, Ichinohe N (2004) Some thoughts on cortical minicolumns. Exp Brain Res 158:265-277.

Schubert D, Kötter R, Luhmann HJ, Staiger JF (2006) Morphology, electrophysiology and functional input connectivity of pyramidal neurons characterizes a genuine layer va in the primary somatosensory cortex. Cereb Cortex 16:223-236.

Schwarz G (1978) Estimating the dimension of a model. Ann Statist 6:461464.

Sherman SM, Guillery RW (2006) Exploring the thalamus and its role in cortical function, Ed 2. Cambridge, MA: MIT press.

Shipp S (2007) Structure and function of the cerebral cortex. Curr Biol 17:R443-R449.

Sjöström PJ, Rancz EA, Roth A, Häusser M (2008) Dendritic excitability and synaptic plasticity. Physiol Rev 88:769-840.

Skoglund TS, Pascher R, Berthold CH (2004) Aspects of the organization of neurons and dendritic bundles in primary somatosensory cortex of the rat. Neurosci Res 50:189-198.

Tamamaki N, Nakamura K, Furuta T, Asamoto K, Kaneko T (2000) Neurons in Golgi-stain-like images revealed by GFP-adenovirus infection in vivo. Neurosci Res 38:231-236.

Tanaka Y, Tanaka Y, Furuta T, Yanagawa Y, Kaneko T (2008) The effects of cutting solutions on the viability of GABAergic interneurons in cerebral cortical slices of adult mice. J Neurosci Methods 171:118-125.

Temereanca S, Simons DJ (2004) Functional topography of corticothalamic feedback enhances thalamic spatial response tuning in the somatosensory whisker/barrel system. Neuron 41:639-651.

Thomson AM (2010) Neocortical layer 6, a review. Front Neuroanat 4:13.

Tomioka R, Rockland KS (2006) Improved Golgi-like visualization in retrogradely projecting neurons after EGFP-adenovirus infection in adult rat and monkey. J Histochem Cytochem 54:539-548.

Valverde F, Facal-Valverde MV, Santacana M, Heredia M (1989) Development and differentiation of early generated cells of sublayer VIb in the somatosensory cortex of the rat: a correlated Golgi and autoradiographic study. J Comp Neurol 290:118-140.

Varga C, Sík A, Lavallée P, Deschênes M (2002) Dendroarchitecture of relay cells in thalamic barreloids: a substrate for cross-whisker modulation. J Neurosci 22:6186-6194.

Welker C, Woolsey TA (1974) Structure of layer IV in the somatosensory neocortex of the rat: description and comparison with the mouse. J Comp Neurol 158:437-453.

West DC, Mercer A, Kirchhecker S, Morris OT, Thomson AM (2006) Layer 6 cortico-thalamic pyramidal cells preferentially innervate interneurons and generate facilitating EPSPs. Cereb Cortex 16:200-211.

Yan J, Suga N (1996) Corticofugal modulation of time-domain processing of biosonar information in bats. Science 273:1100-1103.

Yuan B, Morrow TJ, Casey KL (1986) Corticofugal influences of S1 cortex on ventrobasal thalamic neurons in the awake rat. J Neurosci 6:3611-3617.

Zarrinpar A, Callaway EM (2006) Local connections to specific types of layer 6 neurons in the rat visual cortex. J Neurophysiol 95:1751-1761.

Zhang ZW, Deschênes M (1997) Intracortical axonal projections of lamina VI cells of the primary somatosensory cortex in the rat: a single-cell labeling study. J Neurosci 17:6365-6379.

Zufferey R, Donello JE, Trono D, Hope TJ (1999) Woodchuck hepatitis virus posttranscriptional regulatory element enhances expression of transgenes delivered by retroviral vectors. J Virol 73:2886-2892. 